DELINCUENCIA, PERSONALIDAD Y PSICOPATOLOGÍA 



\title{
DELINCUENCIA, PERSONALIDAD Y PSICOPATOLOGÍA
}

\author{
Vicente Pelechano' \\ Universidad de La Laguna \\ Tenerife (España)
}

\section{RESUMEN}

Ambientalismos (sociológicos y psicológicos) y endogenismos psicológicos y biológicos son incapaces de explicar de forma satisfactoria la delincuencia violenta. Asimismo los modelos constitucionalistas y los temperamentales ignoran la diversidad y versatilidad aparejada con la delincuencia criminal. Se revisa, además (a) la idea de psicopatía y sus diversificaciones, así como sus relaciones con los trastornos de personalidad (DSM); la conclusión es que ni la psicopatía ni los trastornos de personalidad tal y como son presentados en la actualidad ofrecen mucho más que una presentación general demasiado rígida y/o inespecífica como para generar, desde ellas programas de intervención y (b) las tareas y acciones principales del psicólogo en el sistema penal-judicial. Desde el modelo de parámetros se insiste en los factores contextualmotivacionales y cognitivos que ofrecen una posibilidad tanto de diagnóstico como de intervención en adolescentes y adultos, con ilustración de resultados.

Palabras clave: Delincuencia violenta y personalidad, psicopatía, psicopatología en delincuencia, parámetros y delincuencia violenta

1. La correspondencia sobre este trabajo debe dirigirse a vpelecha@ull.es. El trabajo se inscribe en el proyecto SEJ2006-14301/PSIC Consolider, Bien-Star y es una versión ampliada de la conferencia inaugural del Simposio Internacional sobre Psicología y Delincuencia (2008, La Laguna, Tenerife). La responsabilidad de lo expuesto en el trabajo es exclusivamente del autor. 


\section{SUMMARY}

Radical environmental models (from sociology and from psychology) like that endogenous psychological models are considered of a low value in the scientific analysis of criminal behaviour. The concepts of (a) psychopathy and of the personality disorders are revised in order to achieve a psychological and psychopathological picture of criminal behaviour; and (b) the main tasks and possibilities of the psychologist in the justice system are also revised. Both concepts and the tasks revised have some serious problems for an accuracy description, explanation and psychological interventions in criminal behaviour. One different line of research is proposed, from the parameter model, based on the motivational-contextual factors of personality and the interpersonal skills, interpreted as dimensions capable of be trained, inclusive in institutions for criminal people. Some implications on the future of violence people in contemporary society are remembered and a possible forecast on the relative frequency of criminal behaviour among young people in the next future is proposed.

\section{Key words: Criminality and personality, psychopathy, psy- chopathology and criminality, parameters and criminality.}

\section{INTRODUCCIÓN, LIMITACIONES Y PROPÓSITO}

Como posiblemente sucede con la mayoría de temas relevantes, la "psicología de la delincuencia" representa una parcela de conocimiento con muchas teorías (el que sean científicas o no ya es otra cuestión), con demasiados datos incidentales y en muchos casos, se acerca mucho más a un "arte" que a una "ciencia", con detractores y defensores de cuestiones no solamente procedimentales sino sustantivas. El caso es, sin embargo, que la psicología ha hecho acto de presencia en este mundo desde hace tiempo y al rebufo de la psiquiatría (para bien y para mal), lo que ha representado una opción más que puede ayudar a que las decisiones judiciales sean más "jus- 
tas" y adecuadas (el que sean legales es competencia de la propia judicatura). En este trabajo nos restringimos al sistema penal (no se entra en los delitos administrativos ni civiles ${ }^{2}$ ), entendido como un cuerpo de leyes que definen unos tipos de delitos y cómo son tratados los que los cometen. La ley establece una contingencia: especifica que la realización de un acto concreto traerá consigo un castigo legal, lo que asemeja funcionalmente la ley penal a otros sistemas de reglas en la medida en que se trata de reglas explícitas e implícitas que sirven para controlar la conducta en distintos contextos de vida, aunque se ha señalado repetidamente que la ley penal es distinta de otras formas de imperativo social (Sutherland y Cressey, 1970) de manera que debería: (a) ser política en la medida en que es definida por el estado y se aplica a todos los ciudadanos, (b) define el delito en términos de actos concretos y específicos, (c) se aplica (teóricamente) de manera uniforme a todos los ciudadanos al margen de su posición social y (d) propone sanciones penales que pueden hacerse cumplir mediante coacción por los agentes autorizados por el estado (esta coerción ejercida por agentes estatales es, posiblemente, una de las características que diferencian una norma legal de otras normas). En la génesis de estas normas se encuentran las costumbres y tradiciones, la religión y la moral ${ }^{3}$. El papel que juegan estos distin-

2. No es que no se le dé importancia a estos tipos de delitos y/o delincuentes. El problema es que existe un conocimiento escaso respecto a los delitos penales y, por lo que se refiere a los "otros", el volumen de conocimiento es muchísimo menor, con partes sustantivas en las que hay una ausencia total y otras, incluso en el código penal, de la que se conoce apenas nada que sea científicamente demostrable (aunque, eso sí, abundan las aportaciones literarias que se encuentran representadas por más de un género de relatos y de aportaciones cinematográficas.

3. Aunque delito y regla moral son claramente distintos, no cabe duda de la existencia de un elemento moral en las exigencias legales para establecer la responsabilidad de un acusado en un delito. La expresión latina actus non facit reum nisi mens sit rea recoge un elemento básico para inculpar a un ser humano de un acto delictivo. Los elementos esenciales de un delito serían un acto voluntario (actus reus) y la intención para cometer el acto (mens rea). Para bien o para mal, la voluntariedad y la intencionalidad, representan procesos psicológicos muy complejos, y la demostración de su existencia en un acto realizado no es tarea fácil y las deducciones se mueven usualmente a través de claves indirectas. Incluso existen bastantes dudas acerca de la justificación de ambas condiciones y por ello, entran como moduladores de las acciones enjuiciadas. Psicológicamente, el status de las intenciones se encuentra sometido a debate: para los conductistas, las intenciones 
tos dominios en la formulación actual de las leyes es muy relevante y representa una fuente de discusiones y debates, más "políticos" y coyunturales que sustantivos y permanentes, aunque la influencia de la ideología política y de la moral han incidido posiblemente más en los últimos tiempos a la hora del establecimiento de las distintas formulaciones y reformas del código penal.

Desde los primeros tiempos de existencia de la criminología se detectaron dos orientaciones bastantes diferentes entre sí: por una parte, en Europa, poco antes de la primera Guerra Mundial, y como resultado de una alianza entre positivistas, pensadores sociales y psiquiatras, se generó un pensamiento en el que, pese a ciertas influencias ambientalistas, el foco de Lombroso sobre el análisis de la anormalidad individual ocupó un lugar de honor y fue desarrollado básicamente por psicólogos y psiquiatras; en Estados Unidos, por el contrario, su desarrollo estuvo dominado por sociólogos positivistas y el mayor volumen de teorización se orientó hacia las condiciones sociales que "explicaban" y/o gestaban el delito. La orientación europea ha sido criticada como deshumamizadora, insistencia en la política penal ignorando la rehabilitación y promotora de un sistema social de desigualdades, junto a determinismo y tratamiento de la desviación social como irracional. La alternativa defendida por los soció logos radicales busca un cambio social en una dirección socialista, promueve una patologización de la sociedad a la vez que defiende una noción romántica de los delincuentes y asume una liertad sin constricciones a favor de tratamientos ideológicos y análisis simplistas de las relaciones entre delito, justicia criminal y capitalismo, además de encontrarse asentada sobre premisas que impiden una contrastación, siquiera indirecta, de sus afirmaciones.

Una de las derivaciones de este último acercamiento es la concepción del delito como un producto del sistema político concreto

inferidas carecen de un status causal (son subproductos de contingencias ambientales y se refieren a variables verbales relevantes para producir conductas), para los cognitivos representan la base de la conducta propositiva, orientada a metas, que es esencial para la comprensión del funcionamiento humano. Por otro lado, ocuparse tan solo de las acciones, excluyendo las modulaciones psicológicas del acto y del contexto del delito, elimina las consideraciones de la justicia distributiva del sistema jurídico y, en último término, lo convertiría en un sistema de castigo excesivamente duro y equiparable a la ley del talión del código de Hammurabi. 
en el que viven los ciudadanos y, por ello, se define de manera más o menos caprichosa, aunque siempre dependiendo de los intereses y ejercicios del poder del estado (o de la clase dominante). Esta posición resulta muy difícil de aceptar en la medida en que los mismos tipos de conductas antisociales tales como robos, agresiones físicas, asesinatos, violaciones y otras más se encuentran en el cuerpo legislativo de prácticamente todas las sociedades humanas conocidas, al margen del sistema social concreto que cada sociedad haya tenido o tenga en estos momentos. Posiblemente la diferenciación entre delitos con "víctimas" y "sin víctimas" es relevante en este punto: para los primeros existe una práctica universalidad de aceptación; en los segundos entran de lleno cuestiones morales y religiosas que se modifican con el cambio social (por ejemplo, la prostitución y la homosexualidad) y el volumen de poder ejercido por ciertos sistemas de creencias plasmados en posicionamientos religiosos de corte radical. $Y$ es en este segundo tipo en el que se observa una mayor variabilidad social y mayor volumen de cambios, no solamente diacrónicos sino sincrónicos (en unos estados están penalizadas ciertas conductas sexuales y en otros no). Y aquí nos vamos a ocupar del primer tipo.

El objetivo básico de este trabajo consiste en la presentación de las principales aportaciones que ofrece la psicología y en especial la psicología de la personalidad, al mundo de la delincuencia violenta; explícitamente no es una revisión sino una selección desde determinado punto de vista, lo que lleva consigo defender ciertos acercamientos y devaluar otros. En la medida en que los delitos son cometidos por seres humanos, algo debe influir la manera de pensar, sentir y hacer de las personas en la delincuencia, lo que acerca el problema a la psicología de la personalidad en sentido amplio. Al hilo de este propósito deben presentarse unas consideraciones acerca de la manera de entender y de actuar en el caso de la delincuencia. Pero, a la vez, probablemente la mayor repercusión que existe, al menos en los medios de comunicación y en la sensibilidad social, se refiere a un tipo muy concreto de delitos relacionados con la psicopatología y, de manera importante aunque no total, con la denominada "psicopatía", sobre la que, muy posiblemente, se ha publicado más de lo que se debería desde un punto de vista científico. Finalmente, pergeñar, siquiera de manera muy general, algunas sugerencias y 
reflexiones acerca del papel que tienen los "tratamientos psicológicos" en la prevención y eliminación o disminución de los delitos.

Aunque, en el mejor de los casos, se trata de un esquema en el que falta mucha información. La ausencia de datos fiables y precisos acerca de las evoluciones de los delitos en algunas sociedades ${ }^{4}$ ( $y$ en especial la española, aunque no es la única), hace que se tenga que acudir a lo que sucede en otros países, en donde la prohibición alcanza menos cotas de poder. Por lo tanto, lo que sigue debe tomarse como un intento por ofrecer ( $\mathrm{y}$ aclarar, si es posible) conocimientos relevantes en esta área y algunas reflexiones y sugerencias de peso.

\section{UNA REVISIÓN SELECTIVA DE MITOS: EXPLICACIONES SOCIOLÓGICAS RADICA- LES Y ENDOGENISMOS PSICOLÓGICOS}

La existencia de delincuencia ha sido y es objeto de explicaciones de tintes muy distintos que van desde la teología y la mitología hasta la economía y la psicodinamia. Dos tipos de mitologemas se han extendido desde el siglo XIX y no tienen visos de desaparecer en el panorama de las ideas. Uno de ellos se plasma en distintas explicaciones sociológicas en nuestros días que son explicaciones ambientalistas; el otro, apela a pulsiones psicológicas incluso no conscientes para la explicación de la conducta delictiva. Ambos tipos

4. En España la carencia de datos es radical. Resulta muy, pero que muy difícil encontrar datos específicos acerca de delitos, delincuentes, sentencias y procedimientos de cumplimiento de penas, así como reincidencias en un plano de análisis global. Las relaciones entre psicología, psicopatología, sentencias, cumplimiento y seguimiento de los reclusos no son conocidas. $Y$ con todas estas limitaciones, el estado de la psicología en el sistema de justicia carece de bibliografía específica para nuestro entorno cultural. Y otrosí hay que decir respecto a datos sociológicos. En ausencia de datos, en un mundo en el que la invasión ideológica está muy por encima de niveles saludables y tolerables, todo lo que sigue tiene visos de "realidad por analogía". Y con el decidido propósito de animar a que alguien se atreva a "llenar", siquiera de modo absolutamente parcial, ese enorme vacío que existe en la bibliografía española. Las dificultades son tanto de acceso y de interés real en el conocimiento de los sucesos, como de voluntad política para llevarlos a cabo (con la adscripción de proyectos para su realización). En otros países estas dificultades son mucho menores y por ello conocemos algo de lo que sucede en ellos. En España, como en Irán y Honduras, "todo está bien" ¿o no?. 
de explicaciones por atractivas que sean (una por su simplicidad y la otra por su complejidad y plausibilidad literaria), no entran de lleno en el problema de la delincuencia.

(a). Las explicaciones sociológicas tienden a ser ambientalistas radicales y, sustancialmente se trata de teorías económicas en las que el delito es el resultado de la pobreza, relativa o absoluta, de la deprivación y otras causas similares. Se trata de un argumento muy frecuentemente empleado por políticos de distinto signo y que se "asientan" sobre algunos datos, entre ellos, que en las cárceles se encuentran internados muchos más pobres que ricos.

El caso es, sin embargo, que en un análisis sociológico global, resulta muy difícil encontrar datos que avalen esta opción. Así, por ejemplo, por lo que se refiere a la pobreza relativa, desde 1912 a 1974 , el bienestar percibido percibido de la clase muy alta de la sociedad inglesa (el $1 \%$ de la población) bajó del $70 \%$ al $13 \%$ y de la clase alta (el $10 \%$ de la población) pasó de poco más del $90 \%$ a cerca del $40 \%$ (se asume que si los muy ricos perciben una "pérdida", es porque se "reparte" mejor entre la clase media; alternativamente, que existe una mejor distribución de la riqueza, lo que se percibiría como un empeoramiento de las clases altas y muy altas, que perderían parte de sus beneficios y consideraciones). En la última parte de ese período al menos, los delitos crecieron, más que disminuyeron en la sociedad inglesa (lo contrario a lo que podría esperarse por la explicación sociológica); por lo que se refiere a indicadores de pobreza absoluta, entre los años 1979 y 1987 se observó un crecimiento considerable de delitos en Inglaterra. En ese mismo período, la tasa de propietarios de viviendas propias subió de un $50 \%$ de la población a un 66\%; asimismo, al comienzo de este período solamente el $7 \%$ de los votantes eran accionistas de bolsa y, al final del período la cifra había subido por encima del $20 \%$, los propietarios de automóviles subieron desde el $54 \%$ a más del $66 \%$, por lo que se refiere a propietarios de teléfonos se pasó de un $67 \%$ a un $81 \%$ y por lo que se refiere a la etiqueta de "clase media" (por el tipo de trabajo, ingresos y estilo de vida), se pasó de un $30 \%$ a más de un $40 \%$ de la población. Finalmente, la pertenencia a sindicatos (indicador de deprivación y conflicto de clase) pasó en ese período de un 13,3 millones de afiliados a 9,7 millones. Todos estos datos van directamente en contra de 
las predicciones sociológicas simples de una relación causal entre volúmen de delincuencia y pobreza.

Existen otras opciones que, desde la sociología han propuesto distintos mecanismos causales. Entre ellas, la asociación diferencial, la tensión y las teorías sobre subculturas, la teoría del control y la teoría de la etiqueta.

En la asociación diferencial se propone que la delincuencia se debe a la desorganización social y por ello, el origen del delito se encuentra en la existencia de tradiciones y creencias dentro de la sociedad que representan la manera de pensar y hacer de la delincuencia (a mayor exposición a estas ideas, mayor probabilidad de convertirse en delincuentes, Sutherland y Cressey, 1970), que pueden exponerse de manera real o virtual (medios de comunicación social). Esta opción no es susceptible de ser contrastada, se ocupa de la adquisición de tendencias hacia la delincuencia pero no de su puesta en práctica y nada dice acerca de la receptividad diferencial de las personas a este tipo de asociaciones. Y, por otro lado, los supuestos sobre los que se asienta el "aprendizaje social" son imprecisos y erróneos.

En la teoría de la tensión y de las subculturas, Merton (1939) propuso que la desviación social (la no-conformidad con las reglas) refleja las presiones ejercidas por la estructura social; la anomia se refiere a un desajuste entre medios y fines, que se activa cuanto la cultura promueve valores de éxito pero la estructura de clase limita el acceso a esas metas. En el caso de Cohen (1955) se propone que la cultura de la clase trabajadora promueve valores hedonistas que no se ajustan a los de la clase media que se encuentra presente en el sistema educativo y por ello, algunos de ellos, mediante una formación reactiva, adoptan los del gang de los delincuentes. Miller (1958) apela a las influencias de la clase socialmente baja y otros autores, incluso, a la influencia del vecindario. Este tipo de teorías, sobrepredicen el delito entre la clase trabajadora, y la evidencia de la existencia de las subculturas delictivas es muy tenue (los residentes de áreas poco favorecidas no son más tolerantes de los delitos que los residentes en barrios de clase media), la mayor cantidad de delitos, de hecho, se dan entre grupos de dos o tres personas, mientras los delitos violentos suelen ser cometidos por una persona aislada, por lo que el "agrupamiento" que se asume parece poco realista. 
Las denominadas "teorías del control" parten de la idea de que la conformidad a un "orden convencional" requiere ser explicada y el "control" en este contexto hace referencia a los factores restrictivos en el individuo en forma de normas internalizadas (equiparables a entidades tales como ego y superego), y la influencia controladora y autoridad de las instituciones sociales tales como la familia, la escuela o los vecinos. La violación de estas restricciones lleva consigo costos personales en forma de castigos, rechazo social o pérdida de oportunidades; para Hirschi $(1969,1978,1986)$ la conformidad depende de un lazo entre el individuo y la sociedad, cuyos concomitantes son el apego, el compromiso con metas convencionales incompatibles con la delincuencia y la aceptación de la validez moral de los valores convencionales. Sin embargo, poco se dice acerca del origen y desarrollo de este "lazo" y el delito se entiende como la consecuencia natural de la no restricción de las tendencias humanas $y$, en todo caso, el elemento clave psicológico aducido es el autocontrol (un escaso autocontrol se identifica con la delincuencia), que se genera en el ambiente familiar sin influencia de otras instancias sociales, por otro lado, no se reconocen diferencias individuales entre delincuentes y no se proponen medidas independientes del autocontrol propuesto.

Posiblemente una teoría muy extendida es la del etiquetado social y asume que las reacciones sociales a las violaciones de normas pueden alterar el curso de la desviación. En esta teoría, las acciones no son intrínsecamente desviadas, las reacciones de los agentes del sistema legal se encuentran determinadas por los identificadores sociales de los que realizan los actos ilegales (raza, edad o clase social) y no por las acciones realizadas y, finalmente, cuando una persona es identificada públicamente como delincuente, de ahí se derivan resultados negativos para la imagen personal del actor (estigmatización) y por ello se facilita un currículo delictivo. Esta opción ha sido criticada, entre otras cosas, por la hiper-simplificación propuesta entre actitudes, auto-concepto y conducta; por otro lado, la estigmatización no opera de la misma manera para todos los humanos (tiene un escaso efecto sobre delincuentes graves) y la afectación del contacto con el sistema judicial posee un mayor efecto sobre jóvenes de nivel socioeconómico alto, mujeres o delincuentes que cometen su primer delito. 
En definitiva, las teorías sociológicas explican el delito "desde fuera", al margen del delincuente y sus proposiciones poseen un enorme grado de generalidad que las hacen difíciles de ser sometidas al análisis científico. En los intentos revisados y otros de tipo similar, no se explica por qué en una misma situación social objetiva, unas personas se convierten en delincuentes y otras no, incluso en el plano de análisis de países: en la última gran crisis económica el porcentaje de desempleo era mayor en Alemania que en Inglaterra y la tasa de criminalidad era menor en Alemania que en Inglaterra.

Parece claro que aun admitiendo la influencia de las condiciones sociales de tipo distinto sobre los individuos, parece claro que estas variables deben actuar a través de o a partir de la mente de los individuos, por lo que son de especial importancia las interpretaciones psicológicas y, por ello, si ellos se "sienten" que son pobres o deprivados, estos sentimientos darán lugar a conductas muy dispares si la persona es un cristiano muy religioso, un integrista islámico, un marxista contumaz o un fascista. $\mathrm{O}$, dicho de otra manera: los sistemas de valores y creencias resultan de importancia para poder saber qué tipo de acción será tomada por un individuo en uno u otro tipo de circunstancias, asimismo otras parcelas de personalidad resultan de interés.

Una última opción, ésta desde la psicología, ha estado asimismo defendiendo un ambientalismo extremo ${ }^{5}$ : el conductismo radical. Desde Watson al post-skinnerianismo, los conductistas han intentado ofrecer un modelo, siguiendo el empirismo inglés, en el que el ser humano al nacer es una especie de tabula rasa, en la que los apren-

5. Asimismo caben dentro de esta categoría autores como Zimbardo y su reciente libro sobre el "efecto Lucifer" (Zimbardo, 2007), que explica la violencia humana intra-específica apelando básicamente a variables ambientales, que encuentra en situaciones como los acontecimientos que han salido a la luz de Guantánamo una explicación "ambiental" y que encuentran en Rousseau un pensador clásico de excepción. La verdad es que Rousseau tuvo hijos, pero no crió ninguno, los dejó al cuidado de la madre y aquél que haya criado hijos difícilmente puede defender la tesis del ambientalismo de que el ser humano al nacer viene a ser una especie de "buen salvaje" y una "tabula rasa" en el que todo (lo bueno y lo malo) es fruto de aprendizaje. Como he comentado en alguna ocasión, la flauta puede sonar por casualidad, pero por casualidad no "aparecen" los conciertos de flauta de Telemann, o de Albinoni (esto, por lo que se refiere al establecimiento azaroso de contingencias, sin plan establecido). 
dizajes (guiados "desde fuera del sujeto") son los responsables de la variabilidad comportamental. Si se aprenden conductas delictivas, el ser humano se convertirá en un delincuente. No cabe duda que los distintos aprendizajes (que no son todos reducibles a procesos conductistas) desempeñan un papel muy importante en la topografía de la conducta delincuente. Lo que no parece ser verdad es que el ser humano, cuando nace, es un organismo "vacío" en el que cabe "inscribir" cualquier cosa, parece, además, que los seres humanos expuestos ante la misma información y consecuencias, unos aprenden unas cosas y otros otras, que existen disposiciones biológicas que llevan a un humano a aprender más un determinado conjunto de reglas y acciones, mientras que otros aprenden otras y que en definitiva, más de uno de los posicionamientos radicales contemporàneos de esta escuela se han ido convirtiendo más que en una manera de hacer, en una manera de hablar en la que no aparecen definidos operativamente los conceptos que utilizan ni pueden ser controlados los procesos que aducen. De hecho, no existe una demostración experimental en la que todos los participantes (que sean variados) expuestos ante las mismas contingencias, aprendan las mismas cosas y con la misma intensidad y dominio (como se ha dicho en más de una ocasión, la "vivencia" no es una "excrecencia").

No hay duda que, en la actualidad, el acercamiento conductista, en general, representa una opción para la intervención en poblaciones delincuentes. Pero tampoco caben muchas dudas, que estos modelos presentan carencias graves y tipos de procedimientos no siempre viables en el mundo social contemporáneo. Y, por supuesto, que el ambientalismo radical que lo sustenta, no tiene más que una muy magra base experimental (en esta escuela se ha tendido a confundir el que algo pueda hacerse o lograrse de determinada manera con que ésta es la única manera de lograr ese algo).

(b) Frente a estas opciones, lo que hemos denominado endogenismo psicológico asume que la tendencia a cometer un delito y/o convertirse en delincuente es característico de la especie humana, de difícil control y tiene, asimismo diversas caras. Dos tipos de explicaciones se han aducido desde una perspectiva tradicional, y otra está ocupando un lugar preeminente en nuestros días. 
En estas explicaciones, aunque se asume una cierta influencia del ambiente, el poder explicativo se centra en elementos estructurales del funcionamiento psicológico, o de sus posibilitantes. En el caso de la psicodinamia psicoanalítica, la delincuencia depende básicamente de la inadecuada formación y funcionamiento del superego (que puede traer consigo deficiencias en el control del ego y fracaso en el retraso en la gratificación). Las perturbaciones en las relaciones familiares se centran en el complejo de Edipo y la conducta delictiva es el resultado de una patología: un super-ego muy desarrollado produce como resultado una neurosis (la delincuencia representaría una satisfacción sustitutiva de las necesidades pulsionales) y si se encuentra escasamente desarrollado, se ha asociado con la personalidad psicopática. La propuesta de Bowlby (1944) con el apego y sus tipos de problemas amplía el esquema, aunque los resultados que obtuvo este autor no han sido satisfactoriamente replicados. Sin embargo, ni las explicaciones dan lugar a predicciones certeras, el papel de los primeros estadios de desarrollo se encuentra hipertrofiado en detrimento de otros estadios evolutivos que resultan de mayor importancia (como la adolescencia) para la génesis y topografía de la delincuencia, asimismo el papel de la planificación consciente y programada de actos delictivos se devalúa (o se minimiza en función de la existencia y planificación real de pulsiones inconscientes) y el papel del contexto es no solamente minimizado, sino prácticamente reducido a la familia.

Un segundo acercamiento que se ha interpretado demasiadas veces de manera simplista y endogenista ha sido el de los rasgos de personalidad. La investigación sobre los elementos estructurales de la personalidad comenzó con la idea de descubrir los "elementos básicos" del sistema psicológico humano, que debían ser comunes a todos y que explicarían bien de manera aislada o en interacción, la variabilidad de la conducta humana y, entre ella, la conducta delictiva. Influidos por la tradición psiquiátrica y clínica, en general, la delincuencia era básicamente, una psicopatología que debía erradicarse y las principales fuentes de variabilidad a estudiar se encontraban "en" el individuo, su génesis no era motivo prioritario de estudio; las influencias ambientales, aunque implícitamente reconocidas, no eran tematizadas y, en cuanto a teorización, no eran tomadas en cuenta 
puesto que la principal fuente de variación era el individuo ${ }^{6}$. De ahí que la aplicación máxima del acercamiento ha sido el diagnóstico más que la prevención y el tratamiento, y los resultados podrían haberse mejorado si se hubiese ampliado el rango de estudio y aplicación a otros niveles del funcionamiento personal, como sucede en el modelo de parámetros (Pelechano, 1973, 1997, 2000, 2004).

Un tercer acercamiento que asimismo se interpreta de forma excesivamente simplista de manera endogenista es la investigación sobre biología y genética comportamental. Es más que probable que algunas acciones delictivas tengan un sustrato genético-biológico, aunque la topografía comportamental concreta no es probable que sea genética sino fruto de aprendizaje. Es muy posible que la base genético-biológica represente una fuerza a tomar en consideración a la hora de entender las predisposiciones comportamentales hacia la delincuencia, pero no las topografías de la conducta delictiva. No deja de resultar un tanto extraño que la biología no tiene sentido sin el concepto de interacción y/o de transacciones entre un organismo y un medio y, sin embargo, esta interacción no se encuentra plasmada ni en los diseños, ni en la exposición sistemática de resultados empíricos y de su correspondiente interpretación teórica. Por ello, el criterio de validación de pruebas y resultados de laboratorio, siempre corresponde a criterios de funcionamiento psicológico en ambientes concretos e hipercontrolados, alejados de la variabilidad y la incoherencia del sistema social.

Una última consideración la merece el movimiento cognitivo, que pese a su variabilidad, asimismo entiende al individuo como fuente principal de estudio. Los "procesos" aducidos parecen ser independientes de las condiciones de extracción de datos y se generalizan a todas las situaciones posibles, con lo que el papel del ambiente, asimismo, se encuentra devaluado. Y, por otro lado, estos procesos tienden a ser los mismos en los actos delictivos y en los que no lo son (la tesis del isomorfismo de los procesos) y la dinámica que ex-

6. Realmente, más que el individuo, eran las diferencias individuales encontradas en los grupos de individuos (variación interindividual). En más de una ocasión se ha criticado la falacia lógica que representa aplicar a un individuo las diferencias y resultados alcanzados en los análisis diferenciales de grupos (para más de un autor, como Lamiel, los resultados de la psicología diferencial son irrelevantes para la psicología de la personalidad desde presupuestos epistemológicos, conceptuales y metodológicos). 
plica cuando se convierte en delito y cuando no, no parece explicada en detalle a partir de los resultados experimentales de laboratorio.

En definitiva: mientras los sociologismos insisten en formulaciones ambientalistas ingenuas, los endogenismos psicológicos lo hacen sobre tendencias y estructuras de pensamiento en los que el papel del ambiente se encuentra devaluado. Y en todos ellos, la idea de interacción, aunque valorada positivamente a nivel teórico, no se encuentra plasmada en los resultados ni en la integración de resultados y teoría. Esta afirmación, posiblemente, es un argumento de peso para entender la necesidad de realizar esfuerzos de integración entre distintos acercamientos científicos que permitan una mejor comprensión, y de ahí, una ayuda más adecuada para aliviar el problema.

\section{PERSONALIDAD Y DELINCUENCIA: PRINCIPALES FORMULACIONES TRADICIONALES}

(a). El primer tipo de acercamiento se encuentra representado por aquellos que entendían que la delincuencia empapaba todos los niveles funcionales del ser humano y, por ello, los calificativos eran referidos a la totalidad de la persona: ser "delincuente" representaba un tipo específico de ser humano y esta especificidad cubría todos los niveles del funcionamiento personal. Pertenecen a este tipo de modelos y teorías los primeros acercamientos al estudio científico de la delincuencia.

El comienzo, ya muy lejano, de la investigación moderna acerca de delincuencia y personalidad arrancó con Cesare Lombroso (1876, 1917) que propuso un tipo especial de ser humano, el homo delinquens (il reo nato) físicamente parecido al hombre primitivo y que no solamente era una predisposición, sino una predestinación a convertirse en delincuente. Se encontraba caracterizado, entre otras cosas, por una escasa capacidad craneal, frente retraída, protuberancia facial, mandíbulas muy pronunciadas, poco peso cerebral, anomalías en orejas, ojos, labios, dientes o paladar, dedos extra, anormalidades en los genitales (feminidad en hombres y masculinidad en mujeres), infantilismo y zurdera; se exigía la presencia, al menos, de cinco de estas características físicas. Por lo que se refiere a atributos psicológicos, el delincuente se definía como moralmente imbécil (retrasado), falto de remordimiento, de conciencia o de piedad, cínico, impulsivo, 
cruel, y sucio. El propio Lombroso comenzó defendiendo que todos los delincuentes podían identificarse con estos patrones para ir modificando su posición y al final de su vida rebajó la cifra a una tercera parte. Esta opción no se toma en cuenta, en la actualidad.

(b). Siguiendo esta misma línea constitucionalista, las tipologías de Kretschmer y Sheldon y su propuesta de tres grupos de constituciones humanas desde poco antes de la mitad del siglo XX, proponían asimismo un tipo de ser humano (atlético para Kretschmer, mesomorfo-endomórfico en el caso de Sheldon) que tendía a convertirse en delincuente, aunque esta tendencia no era determinante.

Estas propuestas y otras parecidas poseen un valor testimonial y su vigencia en la actualidad es muy pequeña: la carencia de datos contrastados, los defectos en los estudios y grupos de control que han participado y los cambios sustanciales en la medida de elementos físico-constitucionales los hacen poco útiles en la práctica profesional y científica. El desarrollo de la psicología de la personalidad, concomitantemente con el de estos estudios, ha arrojado otra perspectiva, incluso para la interpretación de los resultados alcanzados y, la transformación ha ido en el sentido de estudiar las "pequeñas anormalidades físicas" entre las que se encuentran orejas asimétricas y con alguna malformación, circunferencia craneal atípica, arrugas en la lengua, dedos palmípedos, tercer dedo del pie largo o deformación del paladar, que pueden encontrarse ya en la infancia (Waldrop y Halverson, 1971, Bell y Waldrop, 1982). Los resultados, con todo han sido magros y no especialmente relevantes para la delincuencia.

(c). La propuesta de H. J. Eysenck(1964, 1977, Eysenck y Gudjonsson, 1989).- El modelo de personalidad de Eysenck propone la existencia de un factor cognitivo importante (la inteligencia general) y tres factores temperamentales (extraversión, neuroticismo y psicoticismo). Los cuatro factores poseen un fuerte componente biológico, se consideran como básicos en el funcionamiento personal, con escasas posibilidades de cambio en condiciones de vida usuales y han sido objeto de investigación experimental a lo largo de casi medio siglo. Extraversión significa una escasa capacidad de aprendizaje por condicionamiento clásico (que sería el responsable de la aparición de la conciencia), junto a una buena sociabilidad, amable, activo, aserti- 
vo, buscador de sensaciones, descuidado, dominante; neuroticismo representa inestabilidad emocional, tendencia a ansiedad, depresión, sentimientos de culpa, baja autoestima, tensión, irracionalidad y timidez. Psicoticismo está compuesto por agresividad, frialdad de trato, egocentrismo, impersonalidad, impulsividad, conducta antisocial, carencia de empatía, creatividad y con dureza de trato. El propio Eysenck se queja de que los primeros estudios fueron incidentales, con muchos problemas de diseño y selección muestral, pero que en los últimos trabajos, estos defectos han sido subsanados. A partir de aquí, estas son las principales propuestas que para Eysenck se encuentran asentadas en una fuerte base empírica:

(c.1). El papel de la inteligencia general.- Eysenck asume una práctica asimilación entre inteligencia general y cociente intelectual. Y la hipótesis es que la inteligencia general es menor en delincuentes que en la población en general. Posiblemente ello sea debido a que las personas con una inteligencia general baja tienen pocas alternativas de situarse de manera satisfactoria dentro del sistema social (profesión poco cualificada, escasos ingresos). Sin embargo, el poder causal-predictivo de la inteligencia general sobre la delincuencia es más bien bajo (alrededor de un $5 \%$ de la varianza explicada). La base empírica de esta afirmación se encuentra en los resultados en los que han sido estudiados delincuentes internos en cárceles. Asimismo, parece que en los tests de $\mathrm{Cl}$, los delincuentes presentan una puntuación más alta en las escalas manipulativas que en las verbales.

Ante este tipo de resultados debe tenerse en cuenta (1) que los participantes han sido delincuentes encarcelados (y no todos los delincuentes lo están; es posible que los más inteligentes se encuentren fuera de ella); (2) que la mayoría de resultados proceden de Estados Unidos en donde clase social, inteligencia y etnia se encuentran relacionadas, por lo que "separar" la influencia de cada una de estas variables resulta difícil y los procedimientos estadísticos al uso no siempre han sido aplicados con rigor; (3) alguno de los trabajos citados por el propio Eysenck como evidencia a favor(como el de Ellis, 1989, p.52) se refiere, de hecho, a humanos y no humanos, o se presenta en conjunción con otros tipos de variables ${ }^{7}$; y (4) la

7. Véanse los títulos que no parecen muy relevantes al tema de delincuencia hu- 
parte más sustantiva se asienta en el trabajo de Gordon (1986a y b, Gordon y Gleser, 1974) que propone que la diferencia estadística en inteligencia entre blancos y afroamericanos es la misma que la que corresponde a la prevalencia en delincuencia entre blancos y afroamericanos (a lo que denomina la conmensurabilidad de la inteligencia), lo que científicamente es muy difícil de sostener, por no decir, imposible ${ }^{8}$.

(c.2). Temperamento y delincuencia.- En la última formulación de la teoría, se defiende que la delincuencia y la conducta antisocial se relacionan positiva y causalmente con alto psicoticismo, alta extraversión y alto neuroticismo. Recordemos que se postula que las tres dimensiones poseen una base biológica indiscutible, con niveles bajos de activación cortical en el caso de la extraversión y del psicoticismo (lo que explicaría conductas de asunción de riesgos, búsqueda de sensaciones e impulsividad, que se llevarían a cabo

mana e inteligencia: "Evidence of neuroendrogenic etiology of sex roles from a combined analysis of human, nonhuman, primate and nonprimate mammalian studies", o "The victimful-victimless crime distinction and seven universal demographic correlates of victimful behavior", calificado el segundo como meta-análisis por Eysenck, procedimiento calificado como poco apropiado en la obtención de resultados (Eysenck y Gudjonsson, (1989), p. 56). O se trata de un error de cita o de una falta de especificación en la referencia; en cualquiera de los casos no parece muy adecuado, ni coherente.

8. El argumento es similar al siguiente: en la medida en que el número de doctorados universitarios en cada estado determinado en Estados Unidos y el de los asnos que habitan fuese a la par y las distribuciones fueran equiparables, implicaría que el número de asnos en cada estado depende del número de doctores universitarios. Cámbiense las dos variables expuestas por otras dos cualesquiera y el argumento seguiría siendo el mismo. Lo que se derivaría de la "conmensurabilidad" es que existen variables en el universo que pueden distribuirse y graduar su medida de manera similar... perteneciendo a sistemas distintos o no. El que tengan que ver entre sí debe ser demostrado de forma directa si es posible. $Y$ en todo caso, con un modelo teórico coherente; si ello no deja de ser una coincidencia, como pueden existir muchas en el universo. Recientemente se ha demostrado una "conmensurabilidad" entre producción científica relevante y delincuencia (Kazanawa, 2003) sobre la base de la competitividad, lo que implicaría que los científicos serían, asimismo, delincuentes, o tenderían a serlo. Claro que la muestra de científicos la retrotrae a los siglos XVIII y XIX: los científicos que disminuyen más pronto en creatividad, como los criminales que delinquen menos son los que se casan tempranamente y tienen hijos... Y el análisis, de este porte, sigue y seguirá hasta que las analogías externas se agoten Otra cosa es que estas analogías y correlatos "hagan" sentido científico. 
para alcanzar el nivel óptimo de activación cortical). El neuroticismo (como en la teoría conductista de Hull) actúa como un nivel impulsivo que se multiplica con los patrones de conducta aprendidos de manera que se incrementa la conducta antisocial producida por los rasgos de extraversión y psicoticismo. Se defiende, asimismo, que un procedimiento de aprendizaje que resulta básico para la gestación de la conciencia es el condicionamiento pavloviano: la socialización representa un proceso de aprendizaje en el que la conciencia (desarrollo de conducta altruista y/o de apoyo a los demás) desempeña un papel esencial, por lo que los extravertidos, que aprenden menos por condicionamiento clásico, alcanzarán un nivel bajo de socialización? ${ }^{9}$.

Los resultados alcanzados han obligado a modular la teoría en función de dos elementos básicos: la edad y la heterogeneidad de los delincuentes. Por lo que se refiere a la edad, al menos en la preadolescencia y delincuencia juvenil, aunque psicoticismo siempre es importante, la extraversión es más relevante en estas edades que en fases evolutivas posteriores; el papel del neuroticismo observado es precisamente el opuesto ${ }^{10}$. En cuanto a la heterogeneidad de los delincuentes (es más que probable que los delincuentes violentos y los estafadores se encuentren caracterizados por poseer personalidades distintas).

9. Si esto fuera así, las diferencias entre no delincuentes y delincuentes en extraversión deberían ser significativas... y al menos en España no lo son en muchos casos (véase más adelante). Y además, extraversión debería encontrarse a la base de la conciencia moral... lo que tampoco parece poder ser demostrado, por el momento, en función de los resultados conocidos. Otra cosa que tiende a pasar inadvertida: lo mismo que se aprende la conducta prosocial, se aprende la conducta antisocial ¿cómo aprenden la conducta antisocial los extravertidos si, de hecho, no pueden aprender con facilidad? ¿Por qué las conduictas antisociales se aprenden con mayor facilidad por los extravertidos? A menos, claro está, que se haga explícito el proceso o procesos de aprendizaje que siguen los extravertidos para aprender tan fácilmente la conducta antisocial.

10. Se aducen dos razones: (a) que las muestras de delincuentes adultos se encuentran internas en cárceles y esta situación puede promover una reducción en extraversión y (b) la extraversión, posiblemente es más relevante en el estadio de adquisición de hábitos mientras que el neuroticismo lo sería cuando se multiplica (de acuerdo con Hull: H x D) con hábitos ya aprendidos, esto es, en un estadio posterior. No existen datos experimentales acerca de estas "razones" que se presentan como sugerencias no contrastadas. 
Existen algunos problemas con esta propuesta, que pueden agruparse en aspectos teóricos básicos y en los resultados aducidos como prueba. Por lo que se refiere a la teoría, Eysenck defiende el uso de factores básicos temperamentales como los constitutivos de la personalidad, en detrimento de otros, de tipo más contextual porque defiende que estos factores más contextuales poseen menor poder predictivo, lo que no es verdad y, más bien, lo que parece que sucede es lo contrario. De hecho, desde nuestros propios modelos y datos de los últimos treinta años al menos, la utilización de factores de orden superior o inferior en cuanto a composición factorial a la hora de la predicción depende del tipo de criterio a predecir. Esto es: si lo que se va a predecir es una parcela concreta de conducta y bien delimitada, los mejores predictores no son los factores básicos sino los referidos a ese contexto de vida (Pelechano, 1973, 2000, 2008); por el contrario, si lo que se desea predecir es algo muy básico, relevante y que cueste de modificar (como los sistemas de creencias nucleares), los mejores predictores serían los factores de personalidad más difíciles de modificar. Desde aquí se asumiría que la delincuencia resulta una parcela del funcionamiento personal "básica" y prácticamente inmodificable, lo que no parece corresponder a todos los casos y, además, sería un tanto contradictorio teóricamente establecer predictores "básicos" de delincuencia inmodificables, a la vez que se esgrime la edad (mejor dicho, los sucesos que acaecen a lo largo de la edad) como elemento modulador de la importancia que poseen los factores de personalidad en la comprensión y predicción de la conducta delictiva.

Desde el punto de vista de los resultados experimentales, se juega a la vez a una posición "diferencialista" y a otra "generalista". Por un lado, se aducen resultados de población sueca que ha cometido delitos sin influencia y bajo la influencia del alcohol, lo que no parece una diferenciación de "delincuencia" sino de consumo de alcohol de la que se deriva la delincuencia; por otro, se hace referencia a un estudio en el que participaron cinco grupos de delincuentes (estafadores, contra la propiedad, delitos violentos, conductas inadecuadas y un grupo de residual con distintos tipos de delitos que no eran los anteriores, encontrándose diferencias en las puntuaciones de extraversión, neuroticismo y psicoticismo en unos grupos de delitos, dife- 
rencias que eran distintas en otros, aunque no hay razones claras de estas diferencias que puedan ser contrastadas.

Y, por otro lado, se esgrimen resultados (los más "potentes") acerca de la "generalidad" de la población interna con dos trabajos en los que participaron más de 1500 internos y otros tantos "controles", adultos hombres. Se ofrecen diferencias de medias y nivel de significación de las diferencias. Las diferencias estadísticas, con todo, apenas permiten el establecimiento de un punto de corte con valor predictivo notable (medias en psicoticismo, la variable más "crítica" de 6,55 en el caso del primer grupo de intentos y 6,65 del segundo, mientras que en los controles, la media del primer grupo fue de 4,10 y del segundo de 4,38 ). Con estos resultados los "falsos positivos" y los "falsos negativos" son considerables.

Finalmente, unas palabras sobre la "especificidad". Es verdad que la teoría general eysenckiana no fue elaborada para el estudio de la personalidad criminal sino para intentar alcanzar un estado científico en el diagnóstico psiquiátrico. Así neuroticismo representa tendencia a desarrollar psicopatología ansiosa y depresiva; psicoticismo conducta antisocial y cercana a la psicosis y extraversión, originalmente era entendida como una dimensión "normal", aunque podría ser interpretada en el polo de introversión como cercana a la tendencia a desarrollar esquizofrenia. $Y$ la verdad es que estas dimensiones (o unas muy parecidas) se encuentran en muchos modelos de funcionamiento de personalidad; sin embargo, no son "específicas" de la delincuencia: no parece haber garantía experimental clara e inequívoca que cada una de las dimensiones propuestas, en su puntuación máxima (menos la inteligencia que sería lo contrario) sea una disparadora o causadora de la delincuencia. Y si se juega con dos de tres dimensiones como fuente de diferenciación (usualmente psicoticismo y extraversión), la primera presenta dificultades psicométricas considerables y la segunda, poco tiene que ver con la psicopatología en el modelo eysenckiano original; y las diferencias que se asumen tan claras entre introvertidos y extravertidos por lo que se refiere al aprendizaje pavloviano, los resultados ofrecidos por 
la escuela no son concluyentes, ni tan claramente diferentes, que permitan asentar sobre ellos la génesis psicológica de una entidad como la conciencia, el altruismo y la generosidad. $Y$ existen otras variables y/o dimensiones que se encuentran presentes y no han sido tomadas en consideración por esta teoría, desgraciadamente, porque no entraban "en el modelo teórico" propuesto.

\section{TRASTORNOS DE PERSONALIDAD Y DELINCUENCIA: EL CASO ESPECIAL DE LA PSICOPATÍA.}

(a). La idea de psicopatía.-Existen numerosos testimonios en culturas distintas y en épocas históricas muy anteriores a la actual de que lo que se viene denominando en nuestros días como "psicopatía" ha existido. En los salmos bíblicos se identifican características claves tales como conducta inmoral, orgullo, vanidad, crueldad, sentido de invulnerabilidad, engaño, manipulación y violencia extrema. Los inuit del Noroeste de Alaska lo identifican como kunlangeta ${ }^{11}$ y los yoruba, una tribu de Nigeria, lo denominan aranakan. En todos los casos se hace referencia a personas con fuertes conductas antisociales, fríos y crueles en el trato personal, instrumentalizadoras de los demás, con un nulo sentido de solidaridad y altruismo hacia los demás, y egocéntricos. Pese al predominio de descripciones literarias de hombres, desde la mitología griega hasta el cine contemporáneo han descrito les femmes fatales que hacían daño a los demás siendo seductoras, manipulativas, crueles, egocéntricas, faltas de afecto y de fe (como Medea, Salomé o Manon Lescaut).

La descripción clínica "profesional" del trastorno se remonta a Pinel como un trastorno mental que existe aun cuando el razonamiento se encuentre intacto, fue motivo de análisis por parte de Kraepelin y de Kretschmer, y ha recibido nombres dispares como manie sansa dèlire, monomanie, moral insanity o folie lucide. En la primera parte

11. Murphy (1976) en su estudio sobre los trastornos mentales en las sociedades primitivas identifica al kunlangeta así: "hombre que, por ejemplo, miente repetidamente y engaña y roba cosas y no va a cazar y, cuando los otros hombres no se encuentran en el poblado, tiene contacto sexual con muchas mujeres, alguien que no presta atención a las reprimendas y que está siempre siendo merecedor de castigo por parte de los ancianos. Su presencia es 1 por cada 499 esquimales en la isla" (p. 1026). 
del siglo XX se ampliaron los límites del concepto hasta significar un trastorno de personalidad, en general, que cubría dominios de agresión, impulsividad y conducta antisocial. Las descripciones clínicas de Arieti (1963), Cleckley (1941, 1976) y McCord y McCord (1964) proporcionaron un esquema para identificar a estos individuos como arrogantes, engañosos, abusadores, carentes de respuestas emocionales apropiadas, con respuestas afectivas, además, limitadas y de corta duración, comportamentalmente impulsivos y careciendo de planificación de vida, y los clínicos experimentados añaden problemas con el yo, apego y procesos cognitivos (Cooke, 2004).

(b). Evaluación.- El instrumento más utilizado es la Escala de Psicopatía Revisada (Psycopathy Checklist- Revised, Hare, 1991, 2003), de la que existen versiones para llevar a cabo un primer escrutinio, para adolescentes y que se encuentra basada en la caracterización de Clekley. Se trata de una entrevista semiestructurada con 20 elementos que son calificados en una escala de va de 0 (ausencia del síntoma) a 2 (totalmente presente), con el 1 reflejando dudas respecto a la presencia plena de la característica. El pase de la entrevista exige conocimiento del instrumento, de las técnicas de entrevista y de psicopatología.

Existen interpretaciones distintas de esta escala, asentadas en resultados distintos obtenidos en su composición y que inciden en la conceptuación de lo que significa psicopatía. Así, para Cooke, Michie y Hart (2006), a partir de una crítica del trabajo de validación de la escala de Hare, defienden que psicopatía debe restringirse a un bloque de tres factores aislados con modelos estructurales: (i) estilo interpersonal arrogante (que engloba hablador y encanto superficial, sentido grandioso de valía personal, mentira patológica, fraudulento y manipulador; (ii) experiencia afectiva deficiente (que agrupa falta de remordimiento y culpa, afecto superficial, insensible y falta de empatía y fracaso en aceptar la responsabilidad de las propias acciones) y (iii) estilo comportamental irresponsable e impulsivo (necesidad de estimulación o facilidad para aburrirse, irresponsabilidad, impulsividad, estilo de vida parasitario y carencia de metas realistas a largo plazo). Para estos autores, además, las conductas antisociales son una consecuencia del trastorno y no forman parte sintomatológica de él, por lo que pueden existir psicópatas adaptados al mundo social en contextos sociales muy diversos que van desde la política hasta la medicina (Hall y Benning, 2006; Lykken, 1995). 
Frente a todo ello, el propio Hare y Neumann (2006), tras una revisión de trabajos y un reanálisis de la escala de 2003 insisten en que elementos esenciales de la psicopatía son las conductas antisociales y con modelos estructurales proponen un modelo de cuatro factores que, sustancialmente recoge los tres que se acaban de presentar, al que se añade uno de "conducta antisocial" (pobres controles comportamentales, problemas comportamentales tempranos, delincuencia juvenil, versatilidad criminal y revocación de libertad condicional). Ambos acercamientos se entrecruzan operativamente, aunque con una implicación distinta (en un caso se elimina del concepto la conducta antisocial y en el otro forma parte sustancial de la psicopatía). Las muestras sobre las que se han llevando a cabo los estudios no son solamente norteamericanas, ni inglesas, sino que incluyen otras culturas y diversos tipos de actos criminales que van desde agresiones sexuales, homicidios y asesinatos, atracos y acciones muy violentas. $Y$ en el último caso se incluyen hombres y mujeres.

(c). Tipos aislados de psicopatía.- Uno de los resultados reiteradamente contrastados es que no existe una coherencia clara en cuanto a predicción de criminalidad y conducta psicopática y una de estas posibilidades se debe a que, pese a la diferencia "estructural" en tres o cuatro factores, la verdad es que no se han tomado en cuenta las diferencias entre "psicópatas" (entre otras cosas, porque la relación entre los factores aislados es considerablemente grande, aunque los correlatos y predicciones encontradas con criterios externos son distintos para distintos factores). Lykken $(1995,2006)$ diferencia entre psicópatas (con base temperamental y genética, básicamente se trataría de niños sin miedo o que el miedo no desempeña papel en su aprendizaje) y sociópatas (origen básicamente en el aprendizaje familiar, muchos pueden haberse convertido en ciudadanos productivos y criados por padres responsables, competentes y bien socializados). Los dos presentan fenotipos comportamentales equivalentes, aunque la posibilidad de cambio entre ambos es muy distinta. Para Lykken, debido a la estructura y dinámica de la sociedad contemporánea, el número de psicópatas se mantendría constante, aunque el de sociópatas estaría creciendo, por razones que se expondrán más adelante.

Desde una perspectiva distinta, Karpman (1941) diferenció entre una psicopatía primaria (constitucional, con déficit afectivo básico y 
no susceptibles a recibir ayuda psicológica) y la psicopatía secundaria (que reflejan una perturbación temprana en el aprendizaje social, con ansiedad subyacente, emociones frecuentes de venganza y son susceptibles de ser ayudados psicológicamente). $Y$ en un sentido similar se manifiestan Porter (1996) y Blackburn (1998) ${ }^{12}$.

Se aduce que la psicopatía primaria estaría provocada por un déficit afectivo considerable que se manifestaría en un mayor desapego emocional, y problemas en relaciones interpersonales, con prácticamente nulo riesgo de suicidio y tendencia a conducta agresiva instrumental -agresión para lograr algo-, mientras que los secundarios mostrarían mayor impulsividad y conducta claramente antisocial, con ansiedad, disfóricos y con cierto riesgo de suicidio (o de intentos de suicidio al menos) y su agresividad sería, con frecuencia, no instrumental sino reactiva). Blackburn (1996) ha descrito a los psicópatas secundarios como "personalidades predominantemente límites".

Sin embargo, esta tipología no ha sido capaz de ofrecer un modelo explicativo de la variabilidad de psicópatas internos en cárceles de cumplimiento (los resultados diferenciales reflejan tendencias, pero con un considerable error de predicción por lo que se refiere al papel de la violencia, tipos de crímenes realizados y previsión de actos futuros de este tipo), posiblemente porque se requiere un tipo de investigación más compleja que la realizada hasta el momento (entre otras condiciones que se requieren, se encuentra la necesidad por ofrecer un instrumento de evaluación que recoja la complejidad del fenómeno de la psicopatía, que no por haberse conocido desde hace muchos siglos entre la población humana, ha dado lugar a elaboraciones que permitan una instrumentación útil para detectar la variabilidad observada). Gracias a la escala de Hare se ha avanzado en fiabilidad, lo que, desgraciadamente no ha ido acompañado de un incremento en validez, más bien al contrario.

12. El arranque de Blackburn se encuentra en la distinción propuesta por Megargee sobre delincuentes violentos. La distinción central entre unos y otros es el grado de retraimiento-timidez: el primario es extravertido, confiado en sí mismo/a, dominante y con puntuaciones de bajas a medias, en ansiedad; el secundario es socialmente ansioso, retraído, caprichoso, más sumiso y con puntuaciones bajas en autoestima. La tipología de Blackburn no coincide totalmente con la de Lykken, y existen diferencias, asimismo, con otros autores. Estas diferencias, con todo, no resultan esenciales. 
(d). Psicopatía y trastornos de personalidad.- En la CIE-10, el trastorno disocial de la personalidad recoge falta de empatía, irresponsabilidad y despreocupación por las normas sociales, incapacidad para mantener relaciones personales duraderas, exculpación e incapacidad de sentir culpa y aprender del castigo, lo que aproximaría este trastorno al psicópata primario. De hecho, en la ClE-10 (1992) se dice que el trastorno disocial de la personalidad cubre la personalidad psicopática, entre otras.

En el sistema DSM, segunda versión (1968), el trastorno antisocial de la personalidad se acercaba mucho, asimismo a la descripción de la CIE-10 posterior y, con ello, a la descripción de Cleckley de la psicopatía, aunque la fiabilidad y el consenso en el diagnóstico entre distintos evaluadores era muy baja; en el DSM-III el trastorno antisocial de la personalidad se incluyó en el apartado de investigación (gracias al trabajo de Robins (1966), Feignher et al.(1972) y Spitzer, Forman y Nee, 1972). El esfuerzo tuvo que ser pronto modificado en la versión revisada de esta forma. En el DSM-IV la definición del trastorno de personalidad antisocial cubre solamente en parte, a la psicopatía e incluso a la delincuencia. De hecho se exigen tres criterios al menos para el diagnóstico y si se cumplen el 3 (impulsividad), 5 (desprecio temerario a la seguridad propia o de los demás) y el 6 (irresponsabilidad en trabajo y obligaciones financieras), se puede hacer el diagnóstico de trastorno antisocial de la personalidad en el DSM-IV, aunque podrían no ser delincuentes, podrían ser diagnosticados como adictos o bebedores de alcohol, de manera que esta delimitación del trastorno antisocial de la personalidad ha sido criticado (Lykken, 2006) en el sentido de ser una determinación tan inespecífica como decir de alguien que tiene fiebre, una infección o un trastorno neurológico. Como una cuestión fáctica, Skilling, Harris, Rice y Quinsey (2002) encontraron en una muestra de delincuentes hombres, que las relaciones entre las puntuaciones de la escala revisada de psicopatía de Hare y el trastorno antisocial de la personalidad (DSM-IV) fueron muy altas ${ }^{13}$.

13. Claro que este resultado posee graves carencias en cuanto a metodología. El "diagnóstico" se llevó a cabo a partir del análisis de los archivos policiales y penales de los delincuentes que fueron analizados y la información que puede recogerse de esta manera dista mucho de la que se maneja en una entrevista directa 
Las relaciones entre la psicopatía y el trastorno narcisista de la personalidad son reconocidas hasta el punto que hay autores como Kernberg (1998) que defienden que el trastorno narcisista de la personalidad y el trastorno antisocial pertenecerían a un continuo psicopatológico común. Asimismo se han encontrado relaciones sistemáticas entre el trastorno límite y el trastorno antisocial de la personalidad. En todos estos casos se encuentran componentes antisociales, aunque la razón o motivación para esta conducta antisocial es distinta para cada trastorno de personalidad.

Las relaciones entre psicopatía y ansiedad no han sido siempre coherentes: teóricamente el psicópata carece de ansiedad. Sin embargo a veces se han encontrado relaciones significativas entre trastorno antisocial y ansiedad y este hecho puede deberse a dos razones (a) o bien a que las muestras estudiadas se encuentran encarceladas, lo que puede incrementar el nivel de ansiedad o (b) la existencia de psicópatas secundarios en las muestras, que son sensibles a la ansiedad.

En definitiva: existen problemas conceptuales y metodológicos en la evaluación de la psicopatía; se tienden a reconocer dos tipos de psicópatas (denominados usualmente primarios y secundarios por distintos autores), aunque los autores que utilizan la misma terminología tienden a colocar en cada grupo algunas características que son distintas, o no se encuentran en todos las mismas. Por lo que se refiere a psicopatía y el trastorno antisocial de la personalidad existen relaciones aunque también este último no se encuentra exento de insuficiencias $y$, de hecho, empíricamente cabe asumir tanto su identificación como su diferenciación, aunque parece sensato defender que no siempre las personas identificadas como psicópatas y las diagnosticadas con un trastorno antisocial de la personalidad son las mismas, ni actúan de la misma manera. A pesar de la carga social que posee la expresión "psicopatía", por lo que se refiere a los procesos psicológicos detectados, es muy posible que se encuentren en el mundo social (y en casi todas las escalas sociales) personas más o menos compensadas y que puedan ser identificadas como psicópatas ${ }^{14}$. Asimismo, es posible en-

con la persona a evaluar. De hecho, se advierte que la información entresacada de los archivos es radicalmente insuficiente para el diagnóstico de la psicopatía, aunque no de la conducta antisocial.

14. El principal problema con el que nos encontramos en este punto es que la 
contrarse con una comorbilidad entre ciertas psicopatías y trastornos de ansiedad, trastorno narcisista de la personalidad y trastornos límite (con menos frecuencia pueden encontrarse asimismo casos en los que se encuentre presente un trastorno histriónico de la personalidad).

(e). El caso de la psicopatía en mujeres.- Aunque la mayoría de trabajos publicados se refieren a hombres (en la idea de que se trataría de un trastorno "típico" de hombres), lo cierto es que ya Cleckley (1976) presentó casos de psicópatas mujeres; sin embargo se ha seguido considerando por muchos autores que los rasgos psicopáticos en mujeres (que deben ser los mismos que en los hombres), se entienden como manifestaciones de las expectativas de los papeles femeninos, dado que tradicionalmente el calor humano y la ternura serían características de personalidad tradicionalmente asignadas a las mujeres.

Por lo que se refiere a la prevalencia, mientras en conducta agresiva antisocial parece que existen menos mujeres que hombres (Hartung \& Widiger, 1998), los resultados correspondientes a psicopatía son menos consistentes. La tasa en poblaciones internas en cárceles de cumplimiento en Estados Unidos oscila entre un 9 y un $15 \%$, mientras que en Canadá están entre el 31-32\% (Louth, Hare \& Linden, 1993, Strachan, 1993), aunque el resultado más común es que la puntuación media alcanzada por mujeres en la escala de psicopatía de Hare es un poco menor a la que alcanzan los hombres, la tasa general de psicopatía en mujeres internas se encuentra dentro del rango alcanzado usualmente en los hombres.

Poco se puede decir, hasta el momento, respecto a la similitud o diferencia en estructura factorial del mismo instrumento aplicado a hombres y mujeres (esencialmente las distintas versiones de la escala de Hare) dados los escasos estudios publicados y la incidentalidad y escasez de las muestras que han participado en aquellos en los que se comparan hombres con mujeres. En general puede decirse que, pese a que se ha encontrado una estructura bifactorial en hombres y en mujeres, existen un conjunto de ítems que no saturan en los mismos factores en ambas

evidencia empírica aducida es muy parcial (esto es, personas en las que se encuentran algunos signos, pero no todos, de la psicopatía), evidencias basadas en muestras incidentales y falta de estudio de las relaciones entre los componentes y entre éstos y otros elementos del funcionamiento personal. 
muestras, y, en el caso de las mujeres, los items "pobres controles comportamentales", "impulsividad" y "falta de metas realistas a largo plazo" saturan en los dos factores en una muestra de 103 mujeres (Salekin et al., 1997), lo que se ha obtenido asimismo en otros estudios con análisis factorial confirmatorio (O'Connor, 2001). Asimismo se han encontrado diferencias con los hombres en los ítems de manipulación de personas, problemas comportamentales tempranos, delincuencia juvenil y versatilidad delictiva (Bolt, Hare, Vitale \& Newman, 2004).

Los correlatos de la psicopatía en mujeres con respecto a susceptibilidad de tratamiento, seguimiento de prescripciones y rompimiento de reglas previamente aceptadas en grupos de tratamiento y violencia en el futuro, han sido bastante reiteradas y con ello, la conclusión de que en estas conductas no existen diferencias significativas entre hombres y mujeres psicópatas, en la medida en que se han obtenido resultados inconsistentes del mismo tipo en ambos casos. Se sabe que se presentan más casos de comorbilidad entre psicopatía y ansiedad en mujeres que en hombres (Verona y Vitale, 2006). Además, en general, las mujeres con historia delictiva y violenta, tienden a recibir con más frecuencia que los hombres, un diagnóstico de trastorno límite de la personalidad, más que uno de trastorno antisocial de la personalidad o psicopatía. Goldstein, Powers, McCusker y Mundt (1996) encontraron que en las mujeres con un diagnóstico de trastorno antisocial de la personalidad, frente al mismo diagnóstico en hombres, eran más frecuentes las calificaciones de ser irresponsables como padres, comprometerse con actividades de prostitución y haber sido violentas con compañeros sexuales o niños. Este resultado se ha interpretado, en alguna ocasión (Lilienfeld, 1992) en el sentido de que algunos trastornos que se diagnostican con más frecuencia a mujeres tales como trastorno límite de la personalidad, trastorno de personalidad histriónico y trastorno de somatización pueden representar expresiones de psicopatía en estas mujeres.

En resumen, parece existir un notable solapamiento en mujeres delincuentes entre trastorno antisocial de la personalidad, trastorno de somatización, trastorno límite de personalidad y trastornos histriónico de la personalidad, lo que representaría una psicopatología de síntomas "externalizantes" que en mujeres alcanza cotas superiores a la de los hombres. 


\section{PSICOLOGÍA DE LA PERSONALIDAD CONTEMPORÁNEA EN EL ESTUDIO DE LA DELINCUENCIA}

Además de la formulación de rasgos al estilo tradicional en el estudio de la delincuencia existen un conjunto de opciones que, en unos casos reinterpretan los rasgos desde una óptica más funcional y en otros casos, con incorporación de estudio de procesos y de opciones de corte más cognitivo (como expectativas, prototipos, guiones, estilos de pensamiento y estudios de sesgos mentales), están aportando elementos de cierta relevancia al estudio de la delincuencia. Una gran parte de la denominada psicología forense tiene que ver con la personalidad (tanto en el caso de los delincuentes como de las víctimas y los familiares).

En algunas ocasiones se identifica a la psicología forense con la aplicación de la psicología al sistema legal, en general (Connolly y McKellar, 1963). Sin embargo, en los tribunales, el psicólogo que actúa como especialista, debe ocuparse en la presentación de evidencias lo más directas posible de las personas que haya estudiado y no ofrecer resultados de investigaciones realizadas en otros lugares y personas, sino el fruto de la evaluación realizada directamente sobre el acusado. Esta información debe ser expuesta de manera que pueda ser entendida por los participantes en el acto judicial y usualmente es parte del sistema y no de la defensa ${ }^{15}$.

Asimismo se han utilizado servicios psicológicos en la policía (mucho más en Estados Unidos que en Europa y muy especialmente en España) que tienen que ver con la personalidad y con tradiciones de la psicología de la personalidad. Dos áreas relevantes de participación son la realización de perfiles del delincuente y, por otra, su participación en la interrogación de los acusados, que posee muchas vertientes.

(a). El perfil psicológico de los delincuentes, que se ha denominado a veces "el análisis de la escena del crimen" pretende ayudar a la detención de los delincuentes a partir de extrapolaciones de sus

15. En el caso de actuar para una de las partes (usualmente en la defensa), el papel se cambia en el sentido de que, usualmente se pide información y/o diagnóstico acerca del estado mental del acusado y ahí el impacto de la clínica es muy importante. 
atributos personales sobre datos, claves y pistas encontradas en la escena del crimen. Tiene su origen en la gestación de "historias de vida" o biografías de casos individuales y estudio de personas que fuera propuesto por Murray en los años 30 del pasado siglo y que en la actualidad, dentro de un contexto académico, está siendo cultivado por el grupo de McAdams.

En los 70 del pasado siglo, los departamentos de policía comenzaron a pedir ayuda a los psiquiatras y, poco después, a los psicólogos clínicos, para formular "interpretaciones clínicas" de los delitos que habían cometido delincuentes sin identificar. Posteriormente los métodos de delimitación de perfiles fueron desarrollados por la $\mathrm{Be}$ havioral Sciences Unit de la Academia del FBI en Estados Unidos. El proceso de generar un perfil de un delincuente utiliza tanto información física (datos, rastros, pruebas), como psicológica. Se analiza la escena del crimen en términos disposicionales de la víctima y la presencia o no de secuencias de elementos significativos así como la conducta del delincuente antes y después del crimen. A partir de aquí se infieren un conjunto de hipótesis de trabajo: así, sujetar a una víctima sugiere necesidad de control, mientras que golpearla antes de un acto sexual puede significar una necesidad de activación a partir del dolor o de la sangre. Las características de la víctima, localización del crimen, uso de un vehículo y relación con crímenes anteriores, pueden sugerir algunos atributos sociales y demográficos del delincuente, tales como edad, raza y ocupación laboral.

Dietz (1985) considera la gestación de un perfil como la generación de hipótesis: se trata de asimilación de los datos del crimen, reconstrucción como una conducta, propuesta de hipótesis motivacionales, hipótesis sobre el tipo de persona que ha podido cometer el crimen y la atribución de todas las características que sea posible y además que permitan identificar al posible delincuente.

A la base de todo ello se encuentran los supuestos de que la conducta de un delincuente en la escena del crimen refleja consistencias en su personalidad y modo de actuación. El principal campo de aplicación se ha hecho, a partir de aquí, sobre series de crímenes y ataques sexuales y el $90 \%$ de intentos de perfiles se refieren a asesinatos o raptos. Se ha sugerido que esta actividad de gestación de perfiles es más útil cuando el crimen parece que refleja una psico- 
patología identificable como en el caso de ataques sádicos, raptos o muertes relacionadas con cultos satánicos, aunque se han utilizado también en incendios provocados, llamadas telefónicas obscenas y atracos a bancos. El acento en elementos psicopatológicos parece ser un reflejo del supuesto de que la experiencia clínica puede arrojar cierta luz sobre la "mente del asesino" en crímenes extraños o que no tengan un motivo aparente (como celos, poder, dinero o propiedades). Dada la especificidad de las acciones a analizar, parece que las tipologías clínicas al uso poseen un valor limitado.

Se han propuesto tipologías de perfiles a partir del análisis de materiales provenientes de distintos asesinatos y/o delitos graves. En el FBI, se utiliza una dicotomía entre escenas de crimen organizadas (en las que se puede detectar una planificación y control) frente a no organizadas (que sugieren una conducta azarosa, Ressler, 1986). Durante el crimen, los asesinos organizados utilizan más constricciones sobre sus víctimas, tienen sexo con la víctima antes de matarla, manifiestan un control sobre la víctima y utilizan vehículo. Los asesinos desorganizados tienden a ser menos inteligentes, con niveles menores de ocupación laboral que los organizados, y sexualmente son más inhibidos.

Otra clasificación de asesinos seriales los divide a partir de sus posibles motivos en visionarios (justifican sus acciones por sus visiones de justicia o de grandeza), orientados a la misión que se han fijado (orientan su vida en función de esa meta, prescindiendo en gran medida de todo lo demás), hedonistas (que buscan su propio placer a través del sufrimiento y muerte de sus víctimas) y deseosos de poder y control (su objetivo es demostrar poder y control sobre sus víctimas), aunque estas categorías no se presentan como excluyentes (Holmes, 1989) y parecen más bien, descripciones anecdóticas ex post facto cuyo valor predictivo no ha encontrado, hasta la actualidad, una base sólida.

Se ha propuesto, además (Canter, 1989) que las acciones realizadas durante un asesinato reflejan directamente las interacciones personales que tiene un delincuente con las otras personas. Se asume que los asesinos que matan sin interacción previa con la víctima tienen una vida solitaria. Asimismo, la localización y el patrón espacial de los crímenes que se repiten, pueden ser relacionados con 
características más generales del estilo de un asesino de manera que es posible que los modelos de conducta en un crimen o delito grave puedan relacionarse con características más generales del delincuente. Canter y Heritage (1990) describen un estudio exploratorio con escalamiento multidimensional no métrico de las variables identificadas a partir de informes de 66 víctimas de ataques sexuales y en el que aislaron una estructura de radex bidimensional: en el centro de la estructura del radex se encontraban las actividades más frecuentes tales como introducción en vagina, ausencia de reacción de las víctimas, utilización de un lenguaje impersonal y ataque por sorpresa. La agrupación de variables en el espacio bidimensional representó un apoyo para las teorías que relacionan el ataque sexual con el intento por lograr intimidad, gratificación sexual, agresión, interacción impersonal y criminalidad, aunque se sugieren pesos distintos de estas variables para diferentes delincuentes.

Con mucha frecuencia se ha dicho que la realización de perfiles es más un arte que una ciencia y, de hecho, la evidencia publicada acerca de su validez es muy limitada. Holmes (1989) ofrece datos del informe del FBI del año 1981 y en 192 casos de generación de perfiles, se realizaron 88 detenciones, aunque en ellas, los perfiles ayudaron a la detención solamente en el $17 \%$ de los casos. Algunos datos más recientes elevan los porcentajes en años siguientes hasta un $80 \%$ de ayuda en detenciones, aunque estos resultados se encuentran sometidos a fuertes polémicas y el papel del perfil en todo el aparato policial no se ha aislado en cuanto a poder predictivo.

En resumen: si la tarea de realizar perfiles psicológicos desea alcanzar un status científico superior a la astrología o el espiritismo para ayudar a la policía, los psicólogos deben ocuparse más en demostrar cómo funciona la actividad de generar perfiles y por qué funciona; en este caso, la confusión entre criterios demográficos de identificación y funcionamiento personal sigue siendo la norma, así como la intuición de determinados profesionales, más allá de las "presentaciones" cerradas que pueblan ciertos medios de comunicación.

(b). Un segundo grupo de temas relevantes tiene que ver con los interrogatorios a las personas detenidas. El tema resulta de gran interés por la posible coacción sobre los detenidos y la posibilidad de obtener, con ello, confesiones falsas, lo que ha sucedido en casos 
muy sonados en Estados Unidos (aunque no solamente en aquel país). Irving y Hilgendorf (1980) describen el proceso de interrogación como un proceso de manipulación en la toma de decisiones del sospechoso, incidiendo en los costes y beneficios de confesar. Así, por ejemplo, el entrevistador puede subrayar las consecuencias de ser honesto y el tratamiento posterior que esto va a tener en el juicio por parte del jurado (o del juez), por parte del propio entrevistador y sobre la auto-estima del interrogado. La eficacia de estos recursos se potencia por un ambiente cordial y la impotencia relativa del sospechoso.

Es claro, sin embargo, que muchos interrogados tienen una ansiedad alta en esa situación, y algunos pueden encontrarse intoxicados, encontrarse mentalmente trastornados o ser discapacitados (estos últimos son especialmente susceptibles a ser influenciados por las circunstancias). Gudjonson $(1984,1988)$ ha desarrollado la Suggestibility Scale que sirve para identificar a aquéllos cuyas confesiones pueden ser poco fiables. La escala se relaciona negativamente con inteligencia y asertividad y positivamente con ansiedad-estado y miedo de evaluaciones negativas; también ofrece una buena discriminación entre confesores falsos, y sospechosos que niegan los delitos de manera consistente. Aunque no resuelve el problema acerca de la "veracidad" de todas las informaciones vertidas en un interrogatorio, puede ser una ayuda. Con demasiada frecuencia, los manuales para los interrogatorios de la policía prestan atención a los marcadores que indicarían engaño y así, vaya por caso, se asume que mentir va asociado a ciertos indicadores comportamentales tales como cambio en contacto ocular, cambios en elevación o tono de voz o ciertos gestos, aunque la evidencia experimental controlada ofrece poco apoyo a la fiabilidad de estos indicadores. En Estados Unidos, la policía utiliza con frecuencia el polígrafo y sus resultados son considerados como prueba en algunas partes de Estados Unidos aunque no lo son en la mayoría de estados europeos.

Hay que recordar que el polígrafo no ofrece un patrón con registros únicos y específicos de "mentir" aplicable a todos los casos, sino más bien cambios en activación fisiológica durante el interrogatorio. Los canales registran usualmente resistencia eléctrica de la piel, respiración, tasa cardiaca y presión arterial y aunque existen algunos 
algoritmos para transformar los resultados a expresiones numéricas, la mayoría permanece en un análisis global de los registros. El procedimiento original compara las respuestas a cuestiones relevantes (como por ejemplo ¿ha cometido el crimen?) con respuestas a cuestiones irrelevantes (como ¿hoy es lunes?), aunque a veces se utiliza la variante de preguntar sobre cuestiones que sean todas relevantes (unas relacionadas con el delito y otras no). En otras ocasiones se utiliza el test de cuestión de control en el que las respuestas a preguntas relevantes se comparan con respuestas referidas a conductas sobre el pasado (como por ejemplo ¿alguna vez ha hecho daño a alguien?). En el procedimiento conocido como test de conocimiento de culpabilidad se preguntan cuestiones de elección múltiple sobre el crimen y en donde algunas de las respuestas solamente pueden ser conocidas por quien ha realizado la acción criminal.

Debe señalarse que el polígrafo es empleado, con más frecuencia, por policías que han recibido un pequeño entrenamiento y no por psicofisiólogos especializados. Los distintos procedimientos poligráficos están siendo muy criticados en la medida en que un estudio de control, de eficacia (análisis de resultados poligráficos sin más información que ellos mismos) es muy difícil de encontrar puesto que los resultados forman parte de todo el bloque de interrogatorio realizado. Los resultados publicados de "juicios de inculpación" oscilan entre un $66 \%$ y un $95 \%$ para personas culpables y un $30 \%$ a un $85 \%$ para personas inocentes.

Además de todo ello hay que recordar que los procedimientos de detección de mentiras van más allá de las cuestiones estrictamente científicas y llevan aparejadas situaciones engañosas, inducción de estrés e invasión de intimidad, lo que chocaría con la ética profesional del psicólogo, como han puesto de manifiesto recientes acontecimientos que han visto la luz en ciertos recintos de reclusión.

(c). El psicólogo en los tribunales. Un aspecto muy relevante en la delincuencia es establecer el estado mental del acusado, lo que comenzó siendo tarea de psiquiatras y ya en 1962 y en Estados Unidos se demostró la utilidad del psicólogo como experto; en la década siguiente se creó la psicología forense en ese país. En Gran Bretaña el progreso ha sido menos rápido y en España prácticamente se está "en proyecto". 
La naturaleza de la evidencia se encuentra regida por reglas judiciales. Así, por ejemplo, la regla del "decir-oír" protege al acusado de evidencia incierta o poco segura excluyendo el testimonio que no ha sido obtenido directamente por el experto (así, no se puede presentar información obtenida por un ayudante $u$ otro profesional, ni apelar a resultados de psicología experimental, incluso en muchos tribunales de Estados Unidos, porque los "individuos sobre los que se ha extraído la información no están presentes"). En todo caso, es el juez quien tiene la potestad de aceptar o no el informe del experto. En algunos casos, se ha aducido que el experto no presenta "hechos" de evidencia sino que es alguien que está cualificado por haber realizado estudios relevantes, tiene experiencia en una rama especializada de conocimiento y forma una opinión que representa una probabilidad razonable que no se encuentra al alcance del juez o del jurado medio (por ejemplo, información sobre medicina o psicopatología) por lo que el enjuiciamiento acerca del estado mental del acusado puede ser relevante y el psicólogo clínico es un profesional cualificado para ello. Aunque la coherencia interna del procedimiento judicial en muchos casos deja bastante que desear (por ejemplo, se suele admitir la influencia del estrés en un caso de trastorno mental, pero ese mismo estrés tiende a ser desautorizado en el caso de un acusado que no presente un trastorno mental claro). Además, todavía en nuestros días, las tareas y especializaciones de las distintas especialidades psicológicas no parecen haber calado en el sistema judicial; a veces se pide que actúen profesionales sin una cualificación adecuada ${ }^{16}$ y existe más de una polémica acerca de la adecuación del uso generalizado del psicólogo en el sistema hasta el punto que se ha llegado a defender que su participación debería restringirse a casos claros en los que se requiere un informe técnico para el sistema de justicia.

En todo caso, se pide que, además del conocimiento y experiencia clínica, el psicólogo posea otros tipos de preparación (por ejemplo, conocimiento del sistema judicial). El informe que se presente debe ser claro, relevante y que tenga valor para el caso que se juzga, la información que en él se incluya (Weiner, 1987). Deben

16. Obviamente lo que debería hacer un profesional en estas circunstancias es renunciar a la tarea y remitir a otro que se encuentre cualificado para ello. 
ser explícitas las fuentes utilizadas, así como las pruebas y técnicas empleadas, evitando en lo posible tecnicismos poco útiles (es conveniente aclarar la significación de las expresiones técnicas tales como puntuaciones estándar o la naturaleza de las funciones psicológicas evaluadas) y, finalmente, las conclusiones deben formularse como opiniones fundadas y deben ser explícitas y si es posible, numeradas. Su presencia en los juicios exige el dominio de las técnicas que utilizan los letrados para poder entresacar la información que les conviene, sin matizaciones, con el fin de evitar la manipulación de los juicios emitidos por los expertos.

(d). Componentes de personalidad no básico-temperamentales. Desde el modelo de parámetros (Pelechano, 1973, 1997, 2000, 2008) se han propuesto un conjunto de atributos de funcionamiento personal que no son reducibles a rasgos temperamentales, algunos de los cuales han sido estudiados en relación con la delincuencia. De hecho representa un modelo teórico alternativo a los "grandes modelos estructurales" propuestos por Eysenck y Cattell y a los que se ha añadido una perspectiva más cognitiva (con incorporación de elementos tales como expectativas, dimensiones de solución de problemas, empatía y otros). Aquí nos referiremos a algunas ideas y resultados relacionados con la delincuencia.

El modelo supone (d.1) que el ser humano está formado por conjuntos de sistemas funcionales que son relativamente independientes entre sí; (d.2) que un mismo atributo de personalidad posee características funcionales diversificadas en función del nivel de consolidación-generalización en el que se encuentre y la fase evolutiva en que se evalúe (así, por ejemplo, extraversión o neuroticismo puede evaluarse a un nivel básico-temperamental, intermedio-contextual y situacional); (d.3) que existe un predominio de relaciones no lineales entre variables de personalidad por un lado y personalidad y actos delictivos por otra (por lo que no resulta adecuado un modelo aditivo generalizado en la conceptualización de las relaciones entre procesos, atributos y dimensiones); (d.4) que entre los componentes cognitivos desempeña un papel importante la inteligencia interpersonal y, dentro de ellas, las habilidades interpersonales; (d.5) que las motivaciones humanas se entienden como elementos psicológicos de generalidad y consolidación intermedia-contextual, y desempe- 
ñan un papel predictivo tanto o más importante que los factores básicos temperamentales; (d.6) que todo tipo de estudio debe tomar en cuenta la idea de interacción entre organismo humano y ambiente, sin la cual no es posible construir una ciencia del funcionamiento personal que posea valor explicativo y predictivo de lo que sucede en el caso de la delincuencia; (d.7) se obtiene mayor predicción cuando el criterio a predecir y el predictor se encuentran en el mismo nivel de generalidad-consolidación (para predecir creencias en ideología o religión serían más relevantes los elementos básicos, pero en muchos de los problemas en los que se trata de delincuencia frecuente, serían los elementos contextuales los relevantes); y (d.8) el modelo asume una teoría de inteligencias múltiples $y$, por lo que se refiere al mundo de la delincuencia, importan en especial los componentes de inteligencia sociopersonal-interpersonal, entre los que se encuentran las habilidades interpersonales, aunque estas no son las únicas variables relevantes (el mundo motivacional-contextual se encuentra en un nivel de consolidación-generalización similar).

(i). Variables contextuales-motivacionales y delincuencia adulta.- El primer trabajo fue publicado en 1981 (Pelechano y Guerra) y trató de poner a prueba la viabilidad de una batería de pruebas en la población reclusa. Participaron 106 internos (media de edad de 22 años, la mitad del Instituto Penitenciario de Liria (Valencia) y la otra, de la Cárcel Modelo de Valencia). Se eligieron como controles un grupo de 70 jóvenes estudiantes de un centro de formación profesional de Valencia (media de edad, 18,78 años, un poco más joven que el grupo de internos). De manera individual cumplimentaron una batería de pruebas que evaluaban imagen de sí mismo, motivación laboral realista y motivación hacia el trabajo fantasiosa, junto con una versión del diferencial semántico (en donde autoridad, amor, familia, y yo mismo tenían que ser evaluados). Cabría esperar, en el caso de la psicopatía, una mayor imagen fantasiosa de sí mismo y del trabajo propio en el caso de los internos que de los estudiantes de formación profesional y, en la medida en que se trata de internos en cárcel de cumplimiento, una puntuación mayor en hostilidad y recelo. De hecho, los dos grupos de internos puntuaron significativamente más alto en la extrema valoración de sí mismos, extrema 
valoración del trabajo que realizaban o habían realizado, valoraban más positivamente el mundo laboral (para poderlo instrumentalizar a su favor) y la hostilidad "formal" que indica un recelo muy acusado. Aunque no se pasó ninguna escala específica sobre psicopatía, parecía claro que se trataba de un grupo antisocial y los resultados alcanzados eran coherentes con la presencia alta de psicopatía entre los internos. El análisis discriminante de dos grupos (delincuentes y no delincuentes) arrojó dos funciones significativas que clasificaban correctamente al $79,8 \%$ de los delincuentes: la primera función podía identificarse como de impulsividad-rigidez (extremosidad fantasiosa en la valoración del propio yo y de las acciones que realizan junto a un detallismo y adscripción a principios estereotipados en el mundo social asociado a un desprecio por la autoridad) y la segunda función se identificó con firmeza -estabilidad (factor del diferencial semántico) en rechazo a autoridad, falta de motivación positiva y una baja inteligencia general (prueba de Raven).

Estos resultados abundarían en la propuesta de programas estructurados en los que un sentido de realismo personal acerca del valor de uno mismo, realismo en la tarea que se realiza y reconceptualización de lo que significa autoridad, junto con la sensibilidad de respeto interpersonal parece adecuado, con explícitas normas y especial atención a que no sea instrumentalizado el propio programa en beneficio de los internos de manera poco clara. $Y$ todo dentro del previo análisis del contexto en el que cada individuo debe vivir, lo que implica el análisis de las interacciones y dimensiones atribucionales que se encuentran presentes en estos contextos.

(ii). El mundo de la delincuencia juvenil: variables contextualmotivacionales y habilidades interpersonales.- El dominio de variables contextual-motivacionales ha demostrado su poder predictivo y diferencial en muchos contextos (Pelechano, 2000, 2008). En el mundo de la delincuencia, por otra parte, las relaciones personales ocupan un lugar esencial: forma parte de las distintas acepciones de psicopatía y de trastorno antisocial de la personalidad y, además, en el caso de estas dos opciones, su presencia se detecta ya en la adolescencia (incluso en edades anteriores, a partir de los 6-7 años). De hecho, existe un crecimiento preocupante de la delincuencia violenta entre adolescentes. 
Por lo que se refiere al mundo de las relaciones interpersonales Pelechano (1996) ha presentado un modelo en el que se incluye evaluación e intervención. Se propone la existencia de una inteligencia social-interpersonal de la que se han aislado las siguientes dimensiones: identificación de problemas, asunción de perspectivas distintas, búsqueda de alternativas de solución, previsión de consecuencias (o empatía cognitiva), atribución de causas y segmentalización (descomposición de problemas complejos en otros más simples y manera de resolverlos éstos últimos, así como de ensartar soluciones parciales en otras más generales). Cada una de ellas se encuentra representada por una prueba de diez problemas, adaptada a la edad (existen baterías distintas que se han diversificado desde los 3-4 años hasta la tercera edad). Estas baterías, en adolescentes, se han mostrado sensibles al entrenamiento y han promovido cambio de actitudes hacia la integración de discapacitados y su promoción va aparejada con el crecimiento personal, incremento en tolerancia a la frustración y promoción de ayuda hacia los demás. Asimismo su utilización en clínica individual han demostrado ser útiles en trastornos de ansiedad, fobia social, trastornos de pánico y trastornos de personalidad obsesivo-compulsivos.

Se han realizado dos tesis doctorales en las que, con una lógica de estudios con grupos criteriales se han estudiado las diferencias que existen entre adolescentes "normales" o sin antecedentes y adolescentes detenidos en régimen de reforma (Díaz, 1989, Jodar, 1991). En los dos casos se han utilizado entre tres y cuatro grupos. En el primero, con un total de 675 participantes (286 chicas), repartidos en tres grupos criterio: uno de bien socializados, otros de mal socializados o alumnos problemáticos y un tercero de adolescentes delincuentes menores de edad; en la segunda un total de 567 participantes (237 chicas). La primera de las tesis se llevó a cabo en Valencia y la segunda en Tenerife (Islas Canarias).

Con la participación de grupos criteriales identificados por claves funcionales o sociales se pretendía poder aislar continuidades entre "normalidad" y "delincuencia". En un caso, se identificaron dos grupos de "normales" con la colaboración de los profesores (bien socializados y mal socializados, estos últimos identificados como alumnos-problema, con graves problemas de disciplina y/o agresión a los demás); el 
grupo de delincuentes juveniles estaba formado por 122 (43 chicas) en centros dependientes del Tribunal Tutelar de Menores de Valencia. En el caso de Tenerife se formaron los grupos en función de la zona en que vivían los padres y centros asistenciales: un grupo de adolescentes urbanos que viven en la capital de la provincia y asistían a centros privados o concertados de calidad reconocida, otro de alumnos que asistían a centros rurales, un tercer grupo que vivían y asistían a centros en el extrarradio de la capital de la provincia y pertenecientes a barrios problemáticos; el grupo de delincuentes estaba formado por 19 adolescentes en un centro de reforma.

Todos los participantes cumplimentaron cuestionarios de motivación y la batería de habilidades interpersonales. La motivación evaluaba factores relacionados con el trabajo en los centros educativos, imagen del yo y locus de control.

Un primer gran resultado es que el funcionamiento de los chicos y de las chicas, respecto a los factores motivacionales y a la imagen del yo es distinta. En general, las diferencias para las chicas se presentaron entre "controles" y delincuentes, pero no entre los distintos grupos de control (bien o mal socializados, grupos de residencia y asistencia a centros escolares). Los resultados para chicos arrojaron un considerable volumen de diferencias estadísticamente significativas y en el mismo sentido a las obtenidas en delincuentes adultos: una imagen fantasiosa y extremada sobre el yo propio en el caso de delincuentes, locus de control externo en relaciones personales y en responsabilidad por las acciones realizadas.

Un segundo resultado de interés: en el análisis global de las diferencias en motivación y locus de control entre criteriales "normales" y delincuentes los factores con mayor valor diagnóstico son los siguientes: voluntariedad en el trabajo fantasiosa y extrema (más el grupo de delincuentes), desinterés por el estudio (más el grupo de delincuentes), control externo en exculpación (más en delincuentes) y control interno voluntarista (menos los delincuentes).

Un tercer resultado global cubre el mundo de las habilidades interpersonales: aquí, el grupo de delincuentes, frente al resto se presentó con menos búsqueda de alternativas de solución, y más puntuación que los controles en la percepción de sentimientos de rechazo y de conflicto con los demás, en previsión de consecuencias 
inmediatas y menos puntuación en inteligencia general (escala de Raven). Este resultado de mayor percepción de sentimientos en los demás (en especial sentimientos de rechazo y de conflicto) debería ser tenido muy en cuenta a la hora de promover campañas tanto de tratamiento como de prevención: el joven delincuente parece muy sensible a percibir "lo negativo" en los demás (posiblemente para no ser herido o para poder manipular) y por ello, las campañas encaminadas a promover "empatía" generalizada en delincuencia juvenil pueden tener efectos contraproducentes.

Un cuarto resultado tiene que ver con la comparación entre las relaciones obtenidas en los distintos factores evaluados para cada grupo, lo que daría una idea acerca de la "cercanía" en la estructura personal de cada grupo respecto a las variables evaluadas: a mayor volumen de diferencias, mayor diferencia en la relación entre las variables y, de ahí cabría pensar en una estructura personal distinta. Las mayores diferencias se localizan en el grupo entre adolescentes de extrarradio suburbial y delincuentes, seguido de las comparaciones entre rurales y delincuentes $y$, en último término entre el grupo urbano y el delincuente, lo que indicaría que, por lo que se refiere a la motivación, los adolescentes urbanos de capital poseen una estructura más similar a la de los delincuentes juveniles y, ello llamaría a tareas preventivas que deberían ser distintas en función del poder adquisitivo de los padres y su localización. No debería llevarse a cabo el mismo tipo de prevención en el caso del mundo urbano, del rural y del suburbial. Los resultados motivacionales indicarían que la "motivación" presente en el grupo de delincuentes juveniles es muy distinta a la de los adolescentes que viven en una zona sociológica suburbial similar (una corroboración de que, al menos en cuanto a motivación se refiere, la delincuencia no está bien vista en los suburbios de la ciudad.

Un quinto resultado se refiere a las diferencias en las relaciones en las habilidades interpersonales en los distintos grupos: aquí, la mayor diferencia se encuentra en la comparación entre grupo urbano y grupo delincuente, menos entre rural y delincuente y ninguna diferencia en relaciones entre factores de habilidades interpersonales entre delincuentes y grupo suburbial. En la medida en que las deficiencias en estas habilidades interpersonales se encuentren re- 
lacionadas con la delincuencia (y más arriba se han señalado las candidatas más firmes para ello), este tipo de resultados apoyaría que se debería actuar en las poblaciones suburbiales de manera distinta a la de los núcleos urbanos y rurales en la medida en que en estos dos últimos el fomento de las habilidades llevaría consigo una disminución del peligro a convertirse en delincuentes. Sin embargo, en el caso de la población adolescente suburbial debería actuarse en primer lugar, rompiendo la estructura de las relaciones entre las dimensiones interpersonales puesto que son indistintas a la que poseen los delincuentes juveniles ( $y$ una sugerencia sobre ello sería apoyarse en el mundo motivacional, que es tan distinto entre estas dos poblaciones. Y lo contrario debería hacerse en el caso de los otros dos grupos criteriales "normales" (urbanos y rurales).

Un sexto resultado es que los análisis discriminantes de Valencia arrojaron una función discriminante significativa entre grupos criteriales "normales" y delincuentes. Pero estaba definida por variables distintas en chicos que en chicas. En los chicos la función estaba definida por percepción de sentimientos en los demás, pensamiento causal, segmentalización y búsqueda de alternativas de solución (los criteriales "normales" puntuaban significativamente más que los delincuentes. En las chicas la función discriminante estaba definida por la previsión de consecuencias y la percepción de sentimientos.

Complementariamente, el análisis discriminante entre delincuentes juveniles y no delincuentes en el grupo de Tenerife (en donde se pasó una prueba de inteligencia general) arrojó una función significativa que clasificaba correctamente al $79,5 \%$ de delincuentes juveniles, y el retrato robot de los mismos frente a los "normales" sería el siguiente (de hecho, a partir de las variables que definen la función): menos inteligentes, bajos en neuroticismo y sentimiento de pertenencia a una élite, menos ansiedad ante los exámenes (controles de rendimiento), menos capacidad de segmentalizar los problemas para su posterior solución, más identificación de sentimientos de rechazo en los demás, extravertidos, voluntariedad fantasiosa extremada con autovaloración asimismo extrema, desinteresados en el estudio y el rendimiento convencional, y mayor previsión de consecuencias inmediatas de las acciones. En definitiva, una imagen bastante compleja que insiste en el análisis de las relaciones entre estas dimensiones para no incrementar 
una "negativa" sin desearlo, o impedir el desarrollo de otra "positiva.

(c). Un apunte acerca de la delincuencia femenina adulta.-A. Beleña (1992) desde la Universidad de Valencia puso a prueba la posibilidad y eficacia de un programa de 33 sesiones para mujeres internas en la cárcel de cumplimiento de Sevilla (22 mujeres experimentales y otras 22 controles que no participaron en el programa, aunque sí en cumplimentar las pruebas de habilidades interpersonales en más de una ocasión. Uno de los resultados más llamativos es que el efecto principal del programa en cuanto a socialización es que en el grupo de control se observó un deterioro significativo en el tiempo de duración del programa en prácticamente todas las habilidades interpersonales, mientras que el grupo que participó en el programa mantuvo sus puntuaciones. Además, se observó una mejoría en cuanto a bienestar personal, puntos de referencia sociofamiliares (interactuaban mejor con sus hijos en las visitas, toma en consideración con frecuencia de tareas y acciones a realizar tras la salida de la cárcel) y menor consumo de drogas.

El resultado observado del deterioro en el grupo de control resulta especialmente llamativo porque implicaría que en el sistema penitenciario español, más que posibilitar una rehabilitación, se perturba y deteriora el equipamiento de habilidades interpersonales para establecer y/o mantener relaciones personales de calidad. Si este efecto se da también entre los hombres internos o no se da, es algo que se desconoce hasta ahora y bien merecería un trabajo dedicado a ello.

Aunque los resultados ofrecidos son parciales, representan una opción un tanto distinta respecto a la prevención y al tratamiento. $Y$ son esperanzadores en la medida en que se pueden derivar recomendaciones que ayuden a la recuperación de personas internas. Claro que hace falta mucho más para llegar a protocolizar la intervención, pero son resultados que apuntan todos en direcciones coherentes de actuación.

\section{UNOS DATOS Y UNAS IDEAS MÁS QUE SON PREOCUPANES, AUNQUE, COMO SUELE SUCEDER, DISCUTIBLES}

En general, aunque se ha avanzado en el estudio de la delincuencia violenta, la verdad es que el panorama que existe es com- 
plejo, de retazos de información y lejos, todavía, de ofrecer un protocolo de las dimensiones psicológicas comprometidas con la cuestión así como de una intervención a pase de "protocolización" automática de recursos ${ }^{17}$. Sucede, además, que nos encontramos en una sociedad en cambio continuo y hacer estudios ambiciosos y complejos resulta muy difícil porque en su realización se rozan cuestiones extracientíficas, aunque muy humanas, que deben ser tenidas muy en cuenta. En ausencia de datos españoles es posible que los ofrecidos desde la sociedad estadounidense sirvan para mantener un estado de alerta claro: parece que en los últimos años se ha incrementado el volumen y gravedad de la delincuencia violenta y, en especial de la delincuencia violenta juvenil y, podría llegarse a pensar que los acontecimientos y el aparato legal que identifica nuestro entorno social no ayuden a mejorar esta situación, al menos, en las condiciones de vida actual.

Lykken, tal y como se ha expuesto más arriba, diferencia a los psicópatas, con una base genética más o menos clara, de los sociópatas, que son básicamente de origen familiar y de aprendizaje. $Y$ el grupo que parece estar creciendo es el de los sociópatas. Tracy, Wolfgang y Figlio (1990) estudiaron dos generaciones en Filadelfia, una nacida en 1945 y otra en 1958 y notaron un incremento en el porcentaje de delincuentes violentos, así como en el porcentaje de delitos violentos identificados por la policía cometidos por estas personas. Sobre estos datos y el correspondiente al incremento en trastorno antisocial de la personalidad en Filadelfia desde 1984 (un $50 \%$ ) puede estimarse que el $12 \%$ de hombres nacidos en Filadelfia en 1970 pueden haberse convertido en delincuentes reincidentes a finales del siglo XX. En otro estudio de Robins y Regier (1991) la incidencia de problemas graves de conducta entre hombres nacidos entre 1961 y 1945 fue casi el triple de la incidencia de este problema en hombres nacidos entre 1926 y 1945.

17. Este juicio debe ser entendido en sus justos términos: tenemos una información científica parcial pero, aún así, esta información posee una base mayor y más fundamentada que la que proviene de ideologías o de formulaciones políticas. Aquí, la continuidad en estas "fuentes" y la constatada y reiterada dificultad para llevar a cabo estudios de seguimiento, pese a ello, ofrece probablemente un tipo de información de mayor calidad para la toma de decisiones que la ideología o la coyuntura política o sistemas "morales" inflados de ideología. 
En parte sobre estos datos y en parte sobre datos obtenidos por el propio Lykken (2006) aventura la siguiente elaboración: existe un cierto número de niños que por base genética no tienen miedo o lo tienen en una cuantía muy escasa, estos serían los niños psicópatas y sociópatas, esta carencia de miedo (o su escaso volumen) les lleva a no evitar el dolor, no aprenden de los castigos (tal, asimismo, la tesis de H.J. Eysenck) y por ello, resulta muy difícil que se socialicen (aprendizaje y respeto de las normas de funcionamiento interpersonal y social sin violencia). Por ello poseen un perfil de trastorno antisocial de la personalidad. Como defendía hace unos años S.B. G. Eysenck, Lykken está a favor de una actuación en el nivel de desarrollo lo más pronto posible porque la solución en la vida adulta es muy difícil, por no decir imposible en muchos casos.

La tesis básica es que en Estados Unidos existe una correlación muy alta entre familias monoparentales y trastornos de conducta en niños (antecedente inmediato del trastorno antisocial de la personalidad). Como dato ilustrativo hay que recordar que cerca del $70 \%$ de jóvenes encarcelados en la década de los 80 en Estados Unidos habían sido criados en familias monoparentales (Beck, Kline y Greenfield, 1988, Sullivan, 1992), lo que se ajusta muy bien asimismo con otro dato relevante: menos del $30 \%$ de los niños y adolescentes estudiados en el Oregon Learning Center, con graves problemas de conducta y de aprendizaje, procedían de familias intactas (Forgatch, Patterson y Ray, 1994). Asimismo, en el estudio de Foster (1994) sobre niños con problemas graves de conducta en educación primaria de San Pablo (Minnesota), de aquellos con más de 22 faltas a clase sin justificación, el $70 \%$ eran criados tan solo por madres. En una muestra representativa estatal de Estados Unidos (Kristol, 1994) cerca del $70 \%$ de adolescentes menores de 20 años que tuvieron hijos fuera del matrimonio habían sido criadas sin padre. En España faltan datos que permitan contrastar este tipo de resultados.

En ausencia de tales datos, con lo que conocemos de otros países, la tasa de hijos criados sin padre está alrededor del 30\% (en España la tasa correspondiente a este dato en 2005 era cercana al $27 \%$ ) y esta tasa está creciendo de forma alarmante (en España en diez años se ha llegado a esta cifra comenzando por un 7\%), puede estimarse que el riesgo de patologías sociales que van de la delin- 
cuencia violenta a la muerte (propia o ajena) es siete veces superior para jóvenes criados sin padre que para jóvenes criados por los dos padres biológicos (en Estados Unidos las cifras para blancos y para afroamericanos son similares). Por lo que se refiere a los trastornos límites de personalidad, Paris recordaba hace unos años, que la desestructuración social a la que estamos asistiendo de la familia tradicional traía como consecuencia el crecimiento de casos de este tipo de trastorno que guarda, asimismo, relación con la conducta antisocial y violenta.

Este tipo de resultados debe ser tomado con cautela, sin duda: una correlación no implica nexo causal necesariamente, los resultados son muy generales y pueden incidir sobre ellos otro tipo de etiología como que las familias monoparentales pueden encontrarse viviendo prioritariamente en circunstancias de empobrecimiento personal y cultural, con vecinos problemáticos, las madres solas pueden tener menos tiempo para dedicarse a la crianza y educación de los hijos, pueden ser menos competentes, también, en las tareas de educación, los padres biológicos pueden haber transmitido bases genéticas deficitarias, etc. Un primer acercamiento para el intento de aislar las diversas influencias que inciden en este fenómeno ha sido llevado a cabo por Harper y McLanahan (1998) en Estados Unidos, analizando los resultados de una muestra representativa y longitudinal, el National Longitudinal Survey of Youth (NLSY) para determinar si el incremento en la tasa de delitos entre jóvenes criados sin padre puede ser atribuido al hecho de que tienden a ser más pobres, ser afroamericanos, vivir en el centro de las ciudades o no, o haber nacido de madres diezañeras. Después de controlar todos estos factores, la estructura familiar seguía siendo el predictor más importante para el ingreso en prisión de estos niños antes de los 30 años de edad. Resulta de interés señalar, además, que la presencia de un padrastro, en general, no disminuye el riesgo asociado a la crianza de los hijos por parte de las madres solas y, a la vez, los hijos criados legalmente por padres solos no presentaban más riesgo de delincuencia grave que los criados por ambos padres biológicos. Este tipo de resultados apuntaría a que la madre desempeñaría un papel importante en las tareas de crianza de niños pequeños, pero el papel del padre sería importante para el logro de una socialización satisfactoria. Sin embargo hacen falta más estu- 
dios y con más controles con el fin de poder aislar operativamente, el peso de cada tipo de variable aducida.

En ausencia de tales resultados, valga lo expuesto como hipótesis de trabajo que ha encontrado cierto asentamiento empírico en otros países. Y sería de desear que se llevasen a cabo en España trabajos que permitiese aislar causas y correlatos con el fin de promover maneras de hacer más eficaces en la prevención y tratamiento de la delincuencia.

Y una nota más acerca de este importante tema: explícitamente, en este trabajo, se ha soslayado el peso de variables biológicas en la determinación de esta conducta de delincuencia agresiva en la medida en que, hoy por hoy, a la hora de la aplicación y explicación científica de esta conducta violenta, se pide no solamente presencia o ausencia de una cierta variable (que puede ir desde el análisis bioquímico y hormonal hasta las estimulación de estructuras neurológicas) sino la gradación en la presencia de estos elementos aducidos como "causales", lo que no existe en nuestros días: desde los neurotransmisores hasta la amígdala, vaya por caso, se trata de demostrar la presencia y la cantidad que se encuentran presentes en este tipo de personas. Las respuestas a este tipo de cuestiones, en nuestros días, se encuentran más cercanas a la ficción que a la realidad.

\section{BIBLIOGRAFÍA CITADA}

American Psychiatric Association (1952).- Diagnostic and statistical manual of mental disorders, Washington DC, Author.

American Psychiatric Association (1968).- Diagnostic and statistical manual of mental disorders, ( $2^{\text {nd }}$. edit.), Washington, DC, Author. American Psychiatric Association (1980).- Diagnostic and statistical manual of mental disorders,( ${ }^{\text {rd }}$. edit.), Washington DC, Author. American Psychiatric Association (1987).- Diagnostic and statistical manual of mental disorders, ( $3^{\text {rd }}$ edit. rev.), Washington DC, Author.

American Psychiatric Association (2000).- Diagnostic and statistical manual of mental disorders, ( $4^{\text {th }}$ edit. text rev.), Washington DC, Author. Arieti, S. (1963).- Psychopathic personality: Some views on its psychopathology and psychodynamics, Comprehensive Psychiatry, 4, 301-312. 
Beck, A., Kline, S. \& Greenfeld, L. (1988).- Survey of youth in custo$d y, 1987$, Washington DC, Bureau of Justice Statistics.

Beleña, A. (1992).- Personalidad y habilidades interpersonales en la delincuencia femenina adulta: Evaluación y tratamiento, Tesis doctoral no publicada, Universidad de Valencia.

Bell, R. D. \& Waldrop, M. F. (1982).- Temperament and minor physical abnormalities. En R. Porter \& G. M. Collins (eds).- Temperamental differences in infants and young children, Ciba Symposium $\mathrm{N}^{\circ}$ 89), London, Pitman.

Blackburn, R. (1996).- Psychopathy and personality disorder: implications of interpersonal theory, Issues in Criminology and Legal Psychology, 24, 18-23.

Blackburn, R. (1998).- Psychopathy and the contribution of personality to violence. En T. Millon, E. Simonsen, M. Birket-Smith \& R.D. Davis (eds).- Psychopathy: Antisocial, criminal, and violent behaviour, New York The Guilford Press.

Bolt, D., Hare, R.D., Vitales, J.E. \& Newman, J.P. (2004).- A multigroup item response theory analysis of the Psychopathy Checklist-Revised, Pychological Assessment, 16, 155-168.

Bowlby, J. (1944).- Forty-four juvenile thieves, International Journal of Psychoanalysis, 25,1-57.

Canter, D. (1989).- Ofender profiling, The Psychologist, 2, 12-16.

Canter, D. \& Heritage, R. (1990).- A multivariate model of sexual offence behaviour: Developments in offender profiling, Journal of Forensic Psychiatry,1, 185-212.

Cleckley,H. (1941).- The mask of sanity, St. Louis, MO, Mosby.

Cleckley, H. (1976).- The mask of sanity, $5^{\text {th }}$. Edit. St. Louis, MO, Mosby. Cohen, A. K. (1955).- Delinquent Boys, Glencoe, Free Press.

Cooke, D.J. (2004, March 22-24).- Measuring psychopathy: Things that I have learned so far, Keynote address at the $13^{\text {th }}$ annual Conference of the Division of Forensic Psychology, University of Leicester.

Cooke, D.J., Michie, C. \& Hart, S.D.(2006).- Facets of clinical psychopathy. Toward clearer measurement, En C.J. Patrick (ed).- Handbook of psychopathy, New York, The Guilford Press.

Díaz, A. (1989).- Personalidad y delincuencia juvenile.Un estudio con grupos criterio, Tesis doctoral no publicada, Universidad de Valencia. 
Dietz, P. (1985).- Sex offender profiling by the FBI: A preliminary conceptual model. En M.H. Ben-Aron, S.J. Hucker \& C.D. Webster (ed.).- Clinical criminology, Toronto, Clarke Institute of Psychiatry.

Ellis, L. (1989).- Criminal behaviour and r-s. K selection, Personality and Individual Differences.

Eysenck, H. J. (1964).- Crime and personality, London, Routledge and Kegan Paul.

Eysenck, H. J. (1977).- Crime and personality, $3^{\text {rd }}$. edition, London, Routledge and Kegan Paul.

Eysenck, H. J. \& Gudjonsson, G. H. (1989).- The causes and cures of criminality, London, Plenum Press.

Feighner, J.P., Robins, E., Guze, S.B., Woodruff, R.A., Winokur, G. \& Munoz, R. (1972).- Diagnostic criteria for use in psychiatric research, Archives of General Psychiatry, 26, 57-63.

Forgatch, M.S., Patterson,G.R., \& Ray, J.A. (1994).- Divorce and boy's adjustment problems: Two paths with a single model. En E. M. Hetherington, D. Reiss \& R. Plomin (eds).- Stress, coping and resiliency in children and the family, Hillsdale, NJ, Erlbaum.

Foster,E. (1994).- Baby truants at record high in St. Paul, Minneapolis Star Tribune.7 de abril.

Goldstein, R.B., Powers, S.I., McCusker, J. \& Mundt, K.A. (1996).Gender differences in the manifestations of antisocial personality disorder among residential drug abuse treatment clients, Drug and Alcohol Dependence, 41, 35-45.

Gordon, R. A. (1986a).- IQ-commensurability of black-white differences in crime delinquency, Trabajo presentado en el simposio "Crime and Employment en la reunion annual de la American Psychological Association, Washington, D.C., August.

Gordon, R.A. (1986b).- Scientific justification and the race-IQ -delinquency model. En T.F. Hartnagel \& R.A. Silverman (eds).- Critique and explanation, New Brunswick, Transaction Books.

Gordon, R.A. \& Gleser, L. J. (1974).- The estimation of the prevalence of delinquency: Two approaches and a correction of the literature, Journal of Mathematical Sociology, 3, 275-291.

Gudjonsson, G.H. (1984).- Interrogative suggestibility: Comparison between "false confessors" and "deniers" in criminal trial, Medicine, Science and Law, 24, 56-60. 
Gudjonsson, G.H. (1988).- Interrogative suggestibility: Its relationship with assertiveness, social-evaluative anxiety, state anxiety and method of coping, British Journal of Clinical Psychology,27, 159-166.

Hall, J.R. \& Benning, S.D. (2006).- The "successful" psychopath: Adaptive and subclinical manifestations of psychopathy in the general population, En C.J. Patrick (ed).- Handbook of psychopathy, New York, The Guilford Press.

Hare, R.D. (1991).- The Hare Psychopathic Checklist- Revised, Toronto, ON, Canada, Multi-Health Systems.

Hare, R.D. (2003).- The Hare Psychopathic Checklist-Revised, $2^{\text {nd }}$. Edit., Toronto, ON, Canada, Multi-Health Systems.

Hare, R.D. \& Neumann, C.S. (2006).- The PCL-R assessment of psychopathy. Development, structural properties and new directions, En .J. Patrick(ed).- The handbook of psychopathy, New York, The Guilford Press.

Harper, C.C. \& McLanahan, S.S. (1998).- Father absence and youth incarceration, Trabajo presentado a reunión anual de 1998 de la American Sociologial Association, San Francisco.

Hartung. C.M. \& Widiger, T.A. (1998).- Gender differences in the diagnosis of mental disorders: Conclusions and controversies of the DSM-IV, Psychological Bulletin, 213, 260-278.

Hirschi, T. (1969).- Causes of delinquency, Berkeley, University of California Press.

Hirschi, T. (1978).- Causes and prevention of juvenile delinquency, Sociological Inquiry, 47, 322-341.

Hirschi, T. (1986).- On the compatibility of rational choice and social control theories of crime. En D. B. Cormish \& R.V.G. Clarke (eds).- The reasoning criminal: Rational choice perspectives on offending, New York, Springer Verlag.

Holmes, R.M. (1989).- Profiling violent crimes: An investigate tool, Newburry Park, CA, Sage.

Irving, B.L. \& Hilgendorf, E. L. (1980).- Police interrogation: The psychological approach, Royal Commission on Criminal Procedure, Research Study No.1, London, HMSO.

Jodar, C. (1991).- Variables psicológicas en la evaluación de la delincuencia juvenil: Contrastación de un modelo diagnóstico, Tesis doctoral no publicada, Universidad de La Laguna (Tenerife). 
Karpman, B. (1941).- On the need for separating psychopathy into two distinct clinical types: Symptomatic and idiopatic, Journal of Criminology and Psychopathology, 3, 112-137.

Kazanawa, S. (2003).- Why productivity fades with age: The crime-genius connection, Journal of Research in Personality, 37, 257-272.

Kristol, I. (1994).- Children need their fathers, New York Times, 3 noviembre, p.A15.

Lilienfeld, S.O. (1992).- The association between antisocial personality and somatization disorders: A review and integration of theoretical models, Clinical Psychological Review, 12, 641-662.

Lombroso, C. (1876).- L'uomo delinquente, Milan.

Lombroso, C. (1917).- Crime, its causes and remedies, Boston, Little Brown.

Louth, S.M., Hare, R.D. \& Linden, W. (1998).- Psychopathy and alexitimia in female offenders, Canadian Journal of Behavioral Science, 30, 91-98.

Lykken, D.T. (1995).- The antisocial personalities, Mahwah, NJ, Erlbaum.

Lykken, D.T. (2006).- Psychopathic personality: The scope of the problem. En C.J. Patrick (ed).-Handbook of psychopathy, New York, The Guilford Press.

McCord, W. \& McCord, J. (1964).- The psychopath: An essay on the criminal mind, Princeton, NJ, Van Nostrand.

Merton, R. K. (1939).- Social structure and anomie, American Sociological Review, 3, 672-682.

Miller, W. B. (1958).- Lower class culture as a generating milieu of gang delinquency, Journal of Social Issues, 14, 5-19.

Murphy, J. M. (1976). - Psychiatric labelling in cross-cultural perspective, Science, 191, 1019-1028.

O'Connor, D.A. (2001). - The female psychopath: Validity and factor structure of the revised Psychopathy Checklist (PCL-R) in women inmates, Tesis doctoral no publicada, Florida State University, Tallahassee.

Organización Mundial de la Salud (1992).- CIE-10. Trastornos mentales y del comportamiento, Madrid, Meditor.

Pelechano, V. (1973). - Personalidad y parámetros. Tres escuelas y un modelo, Barcelona, Vicens Vives. 
Pelechano, V (ed.) (1996).- Habilidades interpersonales. Teoría mínima y programas de intervención, 3 volúmenes, Valencia, Promolibro Pelechano, V. (1997).- El modelo de parámetros en personalidad, En V. Pelechano (ed.).- Psicología de la personalidad. Teorías, Barcelona, Ariel.

Pelechano, V. (2000).- Psicología sistemática de la personalidad, Barcelona, Ariel.

Pelechano, V. (2008).- Enfermedades crónicas y psicología, Madrid, Klinik.

Pelechano, V. y Servando, M. A. (2004).- ¿Qué es la personalidad?, Madrid, biblioteca Nueva.

Pinel, R. (1801). - Traitè medico-philosophique sur I'alienation mentale, Paris, Caille et Ravier.

Porter, S. (1996). - Without conscience or without active conscience? The etiology of psychopathy revisited, Aggression and Violent Behavior, 2, 179-189.

Ressler, R.K., Burgues, A.W., Douglas, J.E., Hartman, C.R. \& D' Agostino, R.B. (1986). - Sexual killer and their victims: Identifying patterns through crime scene analysis, Journal of Interpersonal Violence, 1, 273-278.

Robins, N.L. (1966). - Deviant children grown up, Baltimore, Williams \& Wilkins.

Robins, N.L. y Regier, D.A. (1991).- Psychiatric disorders in America, New York, Free Press.

Salekin, R.T., Rogers, R. \& Sewell, K.W. (1997). - Construct validity of psychopathy in a female offender sample: A multitrait-multimethod evaluation, Journal of Abnormal Psychology, 106, 576-585. Skilling, T.A., Harris, G.T., Rice, M.E. \& Quinsey, V.L. (2002).- Identifying persistently antisocial offenders using the Hare Psychopathy Checklist and DSM antisocial personality disorder, Psychological Assesment,14, 27-38.

Spitzer, R.L., Forman, J.B. W. \& Nee, J. (1979).-DSM-III field trials: I. Initial interrater diagnostic reliability, American Journal of Psychiatry, 136, 815-817.

Strachan, C.E. (1993). - The assessment of psychopathy in female offenders, Tesis Doctoral no publicada, University of British Columbia, Vancouver. 
Sutherland, E.H. \& Cressey, D. R. (1970). - Criminology, eight editions, Philadelphia.

Tracy, P.E., Wolfgang, M.H. y Figlio, R.M. (1990). - Delinquency in two birth cohorts, New York, Plenum Press.

Verona, E. \& Vitale, J. (2006). - Psychopathy in women. Assessment, manifestations and etiology. En C.J. Patrick (Ed). - Handbook of psychopathology, New York, The Guilford Press.

Waldrop, M. F. \& Halverson, C. F. (1971).- Minor physical abnormalities and hyperactive behaviour in young children. En J. Hellmuth (ed.).- Exceptional infant: Studies in abnormalities, vol. 2, New York, Brunner/Mazel.

Zimbardo, P. (2007).- The Lucifer effect. Understanding how good people turn evil, New York, Random House. 
